Research Paper

\title{
Murine Sialidase Neu3 facilitates GM2 degradation and bypass in mouse model of Tay-Sachs disease
}

\author{
Volkan Seyrantepe $^{\mathrm{a}, *}$, Secil Akyildiz Demir ${ }^{\mathrm{a}}$, Zehra Kevser Timur ${ }^{\mathrm{a}}$, Johanna Von Gerichten ${ }^{\mathrm{b}}$, \\ Christian Marsching ${ }^{\mathrm{b}, \mathrm{h}, \mathrm{i}}$, Esra Erdemli ${ }^{\mathrm{c}}$, Emin Oztas ${ }^{\mathrm{d}}$, Kohta Takahashi ${ }^{\mathrm{e}}$, Kazunori Yamaguchi ${ }^{\mathrm{f}}$, \\ Nurselin Ates $^{\mathrm{a}}$, Buket Dönmez Demir ${ }^{\mathrm{g}}$, Turgay Dalkara ${ }^{\mathrm{g}}$, Katrin Erich ${ }^{\mathrm{h}, \mathrm{i}}$, Carsten Hopf ${ }^{\mathrm{h}, \mathrm{i}}$, \\ Roger Sandhoff ${ }^{\mathrm{b}}$, Taeko Miyagi ${ }^{\mathrm{f}}$ \\ a Department of Molecular Biology and Genetics, Izmir Institute of Technology, 35430 Izmir, Turkey \\ b Lipid Pathobiochemistry Group (G131) German Cancer Research Center, INF 280, 69120 Heidelberg, Germany \\ ${ }^{c}$ Departments of Histology and Embryology, Ankara University, Medical School, 06100, Sihhiye, Ankara, Turkey \\ d Departments of Histology and Embryology, GATA Medical School, 06100 Ankara, Turkey \\ e Cell Recognition Study, Tohoku Pharmaceutical University, Sendai, Japan \\ ${ }^{\mathrm{f}}$ Miyagi Cancer Center Research Institute, Natori, Japan \\ ${ }^{\mathrm{g}}$ Institutes of Neurological Science and Psychiatry, University of Hacettepe, 06100 Ankara, Turkey \\ ${ }^{\mathrm{h}}$ Center for Applied Research in Applied Biomedical Mass Spectrometry (ABIMAS), Mannheim, Germany \\ ${ }^{\mathrm{i}}$ Institute of Medical Technology (IMT) of Heidelberg University and Mannheim University of Applied Sciences, Paul-Wittsach-Str.10, 68163 Mannheim, Germany
}

\section{A R T I C L E I N F O}

\section{Keywords:}

Tay-Sachs disease

Sialidase NEU3

GM2

Ganglioside

Mouse model

\begin{abstract}
A B S T R A C T
Tay-Sachs disease is a severe lysosomal storage disorder caused by mutations in Hexa, the gene that encodes for the $\alpha$ subunit of lysosomal $\beta$-hexosaminidase A (HEXA), which converts GM2 to GM3 ganglioside. Unexpectedly, $\mathrm{Hexa}^{-/-}$mice have a normal lifespan and show no obvious neurological impairment until at least one year of age. These mice catabolize stored GM2 ganglioside using sialidase(s) to remove sialic acid and form the glycolipid GA2, which is further processed by $\beta$-hexosaminidase B. Therefore, the presence of the sialidase (s) allows the consequences of the Hexa defect to be bypassed. To determine if the sialidase NEU3 contributes to GM2 ganglioside degradation, we generated a mouse model with combined deficiencies of HEXA and NEU3. The $\mathrm{Hexa}^{-/-} \mathrm{Neu}^{-/-}$mice were healthy at birth, but died at 1.5 to 4.5 months of age. Thin-layer chromatography and mass spectrometric analysis of the brains of $\mathrm{Hexa}^{-/-} \mathrm{Neu} 3^{-/-}$mice revealed the abnormal accumulation of GM2 ganglioside. Histological and immunohistochemical analysis demonstrated cytoplasmic vacuolation in the neurons. Electron microscopic examination of the brain, kidneys and testes revealed pleomorphic inclusions of many small vesicles and complex lamellar structures. The $\mathrm{Hexa}^{-/-} \mathrm{Neu3^{-/- }}$ mice exhibited progressive neurodegeneration with neuronal loss, Purkinje cell depletion, and astrogliosis. Slow movement, ataxia, and tremors were the prominent neurological abnormalities observed in these mice. Furthermore, radiographs revealed abnormalities in the skeletal bones of the $\mathrm{Hexa}^{-/-} \mathrm{Neu} 3^{-/-}$mice. Thus, the Hexa $\mathrm{N}^{-/-} \mathrm{Neu} 3^{-/-}$mice mimic the neuropathological and clinical abnormalities of the classical early-onset Tay-Sachs patients, and provide a suitable model for the future pre-clinical testing of potential treatments for this condition.
\end{abstract}

\section{Introduction}

The GM2 gangliosidoses (Tay-Sachs, OMIM 272800; Sandhoff, OMIM 268800; and GM2AP deficiency, OMIM 272750) are a group of rare lysosomal storage disorders caused by mutations in three different genes: Hexa, Hexb, and Gm2ap. The Hexa and Hexb genes encode the $\alpha$ and $\beta$ subunits, respectively, of $\beta-N$-acetylhexosaminidase, (HEXA, $\alpha \beta$, EC 3.2.1.52), which form a complex with GM2AP to hydrolyze GM2 ganglioside and remove $N$-acetylgalactosamine (Gravel et al., 2001). GM2 ganglioside is a glycosphingolipid that serves as an intermediate in complex brain ganglioside (mainly GM1a, GD1a, GD1b, and GT1b) biosynthesis and degradation (Kolter and Sandhoff, 1999). Complex brain gangliosides are most abundant in the cell membranes of neurons, where they contribute to axon-myelin interactions, $\mathrm{Ca}^{2+}$ homeostasis, and the activity of a diverse range of trans-membrane receptor signaling pathways (Regina and Hakomori, 2008; Schnaar, 2010; Ohmi et al.,

\footnotetext{
* Corresponding author at: Izmir Institute of Technology, Department of Molecular Biology and Genetics, Gulbahce Mah, Urla, 35430 Izmir, Turkey.

E-mail address: volkanseyrantepe@iyte.edu.tr (V. Seyrantepe).
} 
2012; Nordstrom et al., 2013; Allende and Proia, 2014). Therefore, the central nervous system is the most impacted organ in patients because of the high levels of the HEXA substrate, GM2 ganglioside. Tay-Sachs disease is clinically similar to Sandhoff disease and GM2-activator deficiency (Sandhoff, 2016). The classic infantile acute form begins early in infancy and leads to death by four years of age. It is also known as early-onset type I GM2 gangliosidosis (B variant or pseudo-AB variant). Variable phenotypes with a range of disease severities and ages of onset result when low levels of residual HEXA activities are present (Sandhoff and Conzelmann, 1984). Juvenile subacute (the onset can be between two and ten years of age) and chronic (onset in adult life) forms of the disorder can occur. Patients with the rapidly progressive and acute form of this disorder exhibit a total or near-total loss of HEXA activity that is mostly due to missense or nonsense mutations. Diagnosis can be made by a number of methods, such as measurement of HEXA enzyme activity using synthetic substrates. The clinical symptoms of progressive neurodegeneration and developmental delay are caused by the accumulation of GM2 ganglioside in lysosomes, which leads to early cell death in Tay-Sachs patients.

Two independent studies attempting to generate mouse models of GM2 gangliosidoses by targeting the mouse Hexa and Hexb genes yielded unexpected results (Phaneuf et al., 1996; Yamanaka et al., 1994). The disruption of Hexb resulted in a severe neurological phenotype similar to Sandhoff disease; however, the disruption of Hexa resulted in nearly normal mice rather than a severe early-onset neurological phenotype. These findings were explained by the presence of one or more sialidases in mice that can remove sialic acid from GM2 ganglioside to create GA2 ganglioside, which can then be degraded by the HEX B $(\beta \beta)$ present in HEXA- deficient Tay-Sachs mice (Fig. 1A) (Sango et al., 1995; Yuziuk et al., 1998). The generation of a HEXBdeficient Sandhoff disease model in mice was useful for the initial evaluation of potential therapies for the GM2 gangliosidoses. However, $\mathrm{Hexa}^{-/-}$mice have proven to be of little value as a model for Tay-
Sachs disease because they do not exhibit a severe buildup of brain GM2 or the abnormal behavioral manifestations that are seen in human Tay-Sachs patients.

Sialidases or neuraminidases (EC 3.2.1.18) are a family of exo-glycosidases that cleave non-reducing sialic acids that are glycosidically linked to the saccharide chains of glycoproteins, glycolipids or oligosaccharides. Sialidases have been implicated in crucial biological processes, including regulation of proliferation, control of cell adhesion, modeling of myelin, and metabolism of glycoconjugates (Monti et al., 2010). In humans, sialidases are encoded by multiple genes and they differ in terms of their optimal working $\mathrm{pH}$ values, kinetic properties, substrate specificities, and preference for sialic acid linkage. Based on their subcellular localization, the sialidases can be categorized as lysosomal (NEU1), cytosolic (NEU2), plasma- membrane-associated (NEU3), or lysosomal/mitochondrial or intracellular-membrane-associated (NEU4) (Miyagi and Yamaguchi, 2012). NEU1, NEU3, and NEU4, are capable of hydrolyzing sialic acid residues from gangliosides. However, the lysosomal sialidase NEU1, is part of a multi-enzyme complex with $\beta$-galactosidase and protective protein-cathepsin A (Pshezhetsky and Ashmarina, 2001) and is inactive outside of the complex, and it undergoes rapid degradation in cells deficient in cathepsin A in the genetic disease galactosialidosis (Bonten et al., 2009). NEU1 is the only mammalian sialidase that is clinically relevant with NEU1 deficiency resulting in the accumulation of sialoglycoconjugates, and extensive lysosomal vacuolization, causing excessive tissue degeneration and a pediatric neurosomatic disorder (d'Azzo et al., 1982). NEU3 is highly active toward gangliosides, and in addition to being located on the plasma membrane, it can also be found facing inward on the membranes of endosomes and lysosomes (Miyagi et al., 1999; Monti et al., 2000; Zanchetti et al., 2007; Albohy et al., 2010). The principal substrates of NEU3 are GM3 and disialogangliosides such as GD1a (Papini et al., 2004; Ha et al., 2004) and it exhibits poor activity toward GM1 or GM2, at least in vitro (Wang et al., 2001). NEU4 is targeted to
A

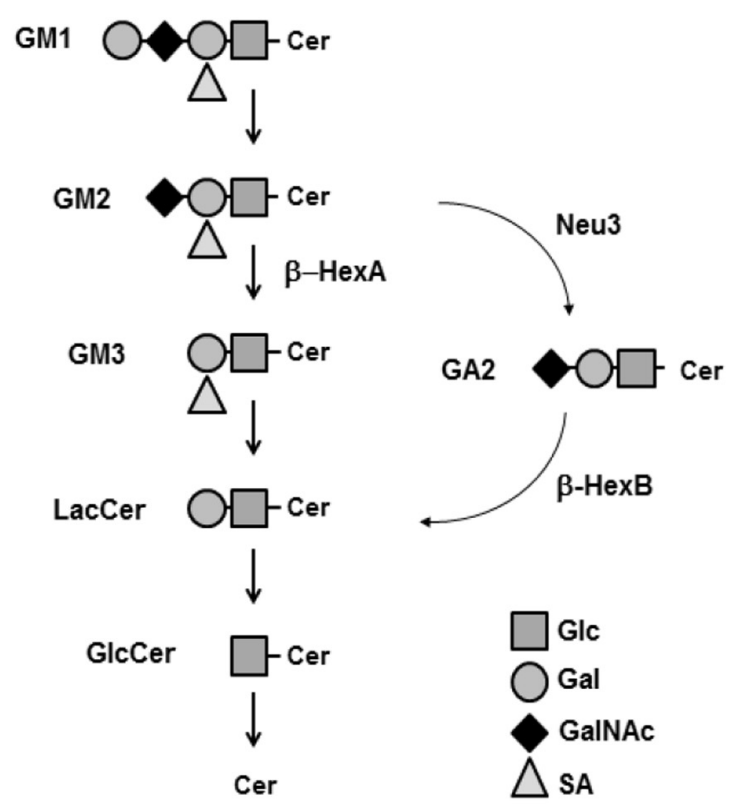

B

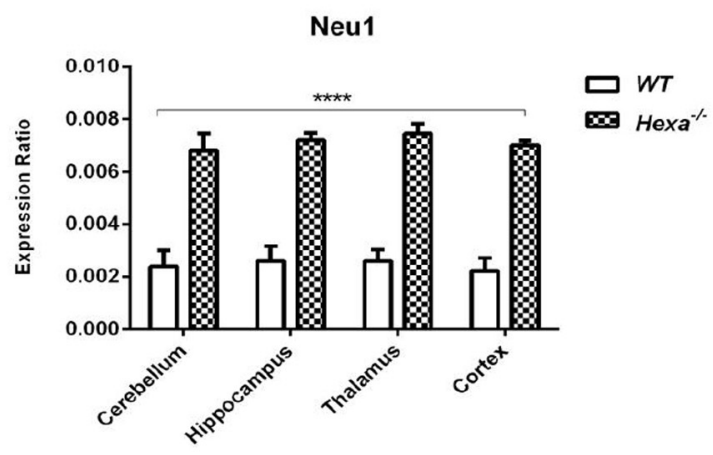

C

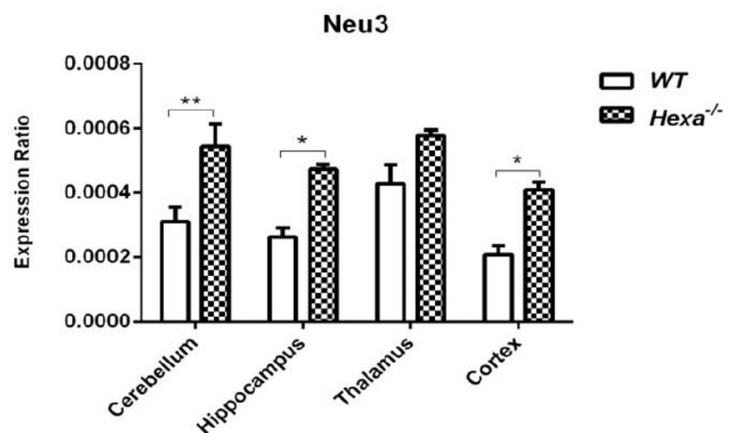

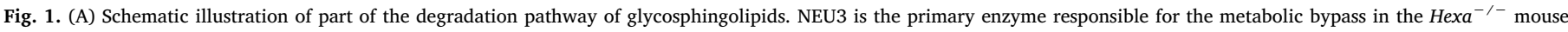

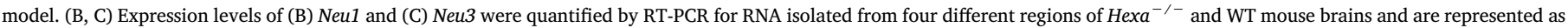

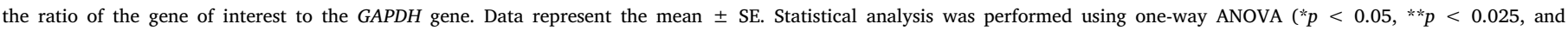
$* * * * p<0.0001)$. 
Table 1

UPLC gradient used for the LC-ESI-MM/MS analysis of GSLs.

\begin{tabular}{lllll}
\hline Time (min) & Flow (mL) & Solvent A (\%) & Solvent B (\%) & Curve \\
\hline Initial & 0.45 & 100 & 0 & Linear \\
0.25 & 0.45 & 100 & 0 & Linear \\
1.00 & 0.45 & 50 & 50 & Linear \\
5.50 & 0.45 & 0 & 100 & Convex \\
6.50 & 0.45 & 0 & 100 & Linear \\
7.00 & 0.45 & 100 & 0 & Linear \\
7.50 & 0.45 & 100 & 0 & Linear \\
\hline
\end{tabular}

subcellular compartments but is more widely distributed. It has been reported to be found in the endoplasmic reticulum (ER), mitochondria (Yamaguchi et al., 2005), and lysosomes (Seyrantepe et al., 2008). In our previous study, we also reported that NEU4 exhibits activity toward complex gangliosides and GM2 ganglioside in vitro (Seyrantepe et al., 2008). In an attempt to elucidate whether the sialidase NEU4 is involved in bypassing the metabolic defects in $\mathrm{Hexa}^{-1-}$ mice, we generated a $\mathrm{Hexa}^{-1-} \mathrm{Neu}^{-/-}$mouse model. The relatively mild phenotype in that model underscored the sialidase NEU4 as a modifier gene rather than a major player, leaving unclear the identity of the
A

\section{Male Mice Weight Measurement}

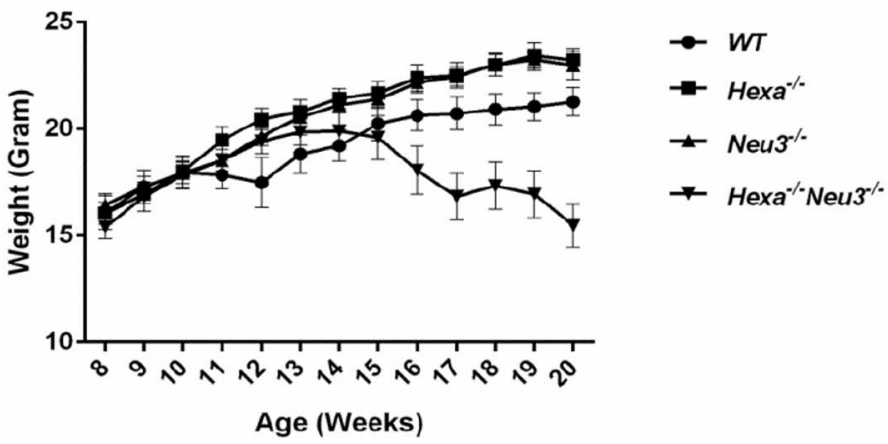

B

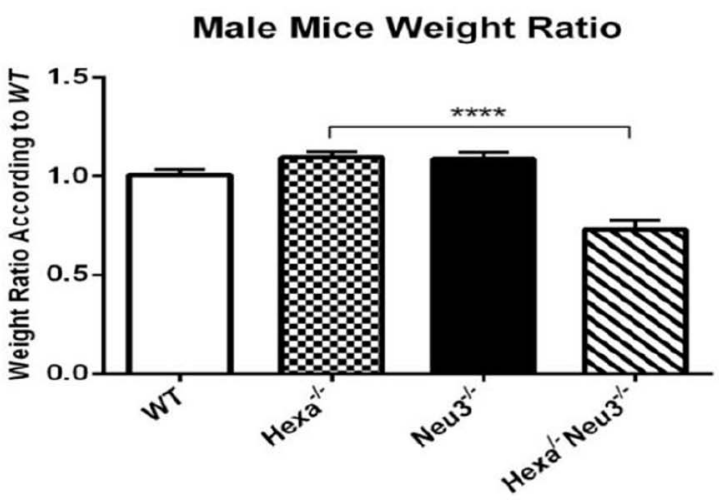

C

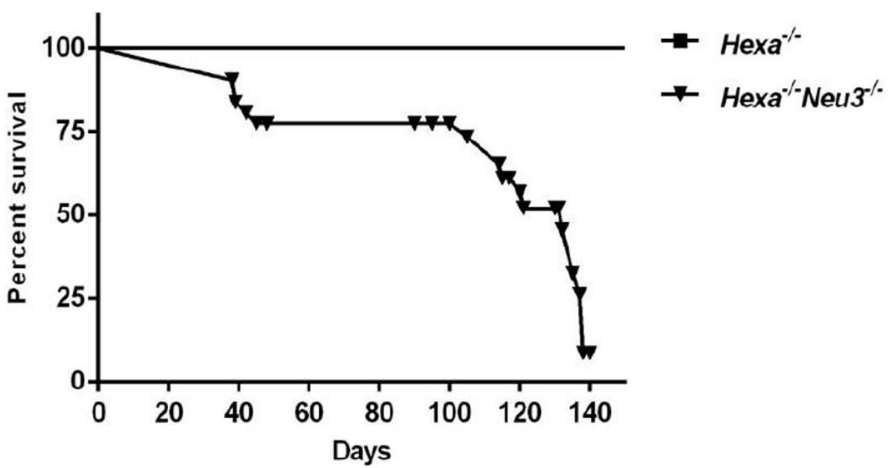

D

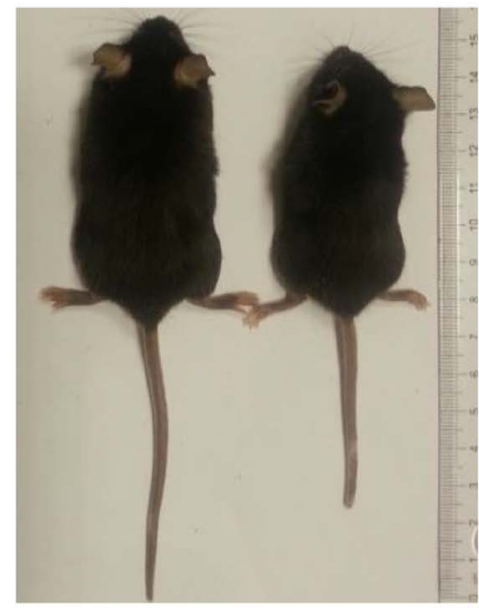

E

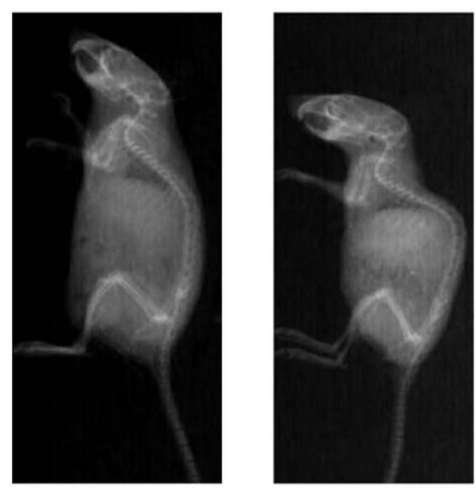

F

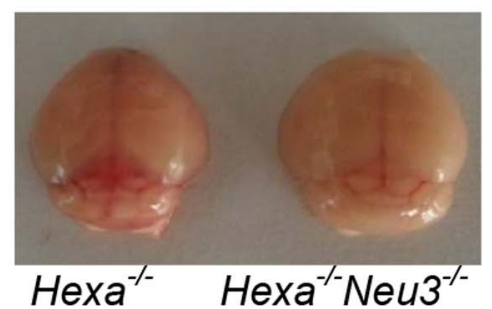

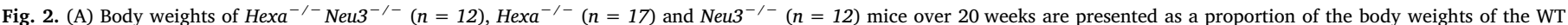

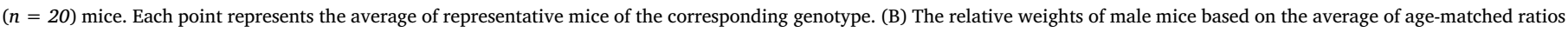

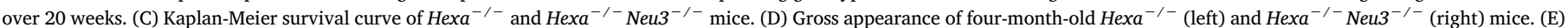

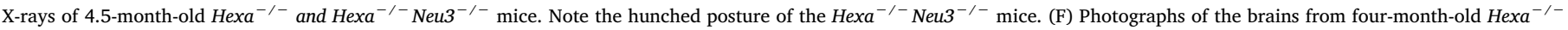
(left) and $\mathrm{Hexa}^{-/-} \mathrm{Neu}^{-/-}$(right) mice. Note that the brain of the Hexa ${ }^{-/-} \mathrm{Neu}^{-/-}$mouse is $15-20 \%$ bigger in size than that of its $\mathrm{Hexa}{ }^{-/-}$littermate. 


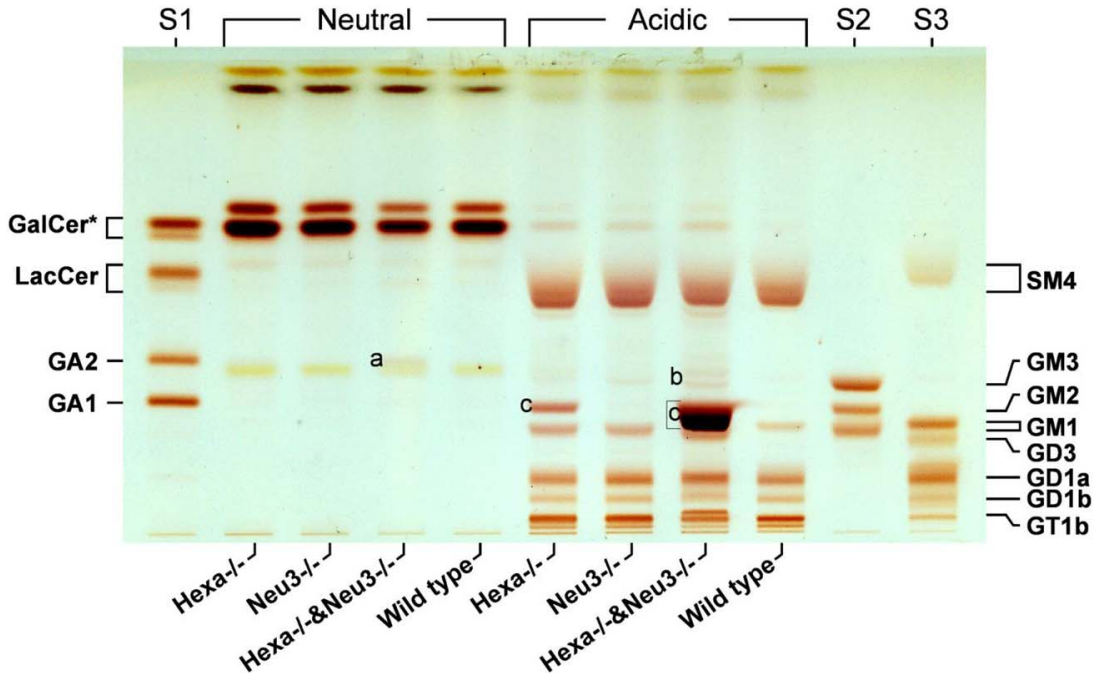

Fig. 3. Accumulation of ganglioside GM2 in the brains of $\mathrm{Hexa}^{-1}$ $\mathrm{Neu} 3^{-/-}$mice. The neutral (left) and acidic (right) fractions of sphingolipids from brain tissue samples were separated by HPTLC and stained for glycolipids. The neutral and acidic glycosphingolipid standards are indicated on each side. (A) GA2 appears slightly above the yellowish nonspecific staining of sphingomyelin. (B) The GM3 double band appears in the brains of $\mathrm{Hexa}^{-/-} \mathrm{Neu}^{-/-}$mice. (C) GM2 accumulation in the brains of $\mathrm{Hexa}^{-/-}$(mild) and $\mathrm{Hexa}^{-}$ ${ }^{-} \mathrm{Neu} 3^{-/-}$(strong) mice. Standards are as follows, from top to bottom. S1: GalCer* (double band), LacCer, GA2, and GA1 *: Contains ceramide anchors with alpha-hydroxy fatty acids. S2: GM3, GM2, GM1a. S3: from porcine brain, sulfatide SM4s, and the gangliosides GM1a, GD3, GD1a, GD1b, and GT1b. These data are representative of three samples. predominant sialidase in GM2 catabolism in $\mathrm{Hexa}^{-/-}$mice (Seyrantepe et al., 2010).

In this study, we generated a mutant mouse line in which both Hexa and Neu3 genes have been genetically deleted in order to explore the metabolic bypass mechanism in the ganglioside degradation pathway. These mice displayed massive storage of GM2 and exhibited clinical, pathological, and biochemical abnormalities similar to Tay-Sachs patients. Our analysis of these mice indicates that $\mathrm{Hexa}^{-/-} \mathrm{Neu}^{-/-}$mice could serve as a useful model for Tay-Sachs disease and contribute to our understanding of cellular pathologies that drive the progression of the disease by revealing prominent neuroinflammation caused by abnormal lysosomal accumulation of GM2 ganglioside in neurons.

\section{Materials and methods}

\subsection{Generation of double knockout mice}

Tay-Sachs disease mice $\left(\mathrm{Hexa}^{-/-}\right)$on a $129 / \mathrm{Sv}$ background and NEU3-deficient $\left(\mathrm{Neu}^{-/-}\right)$mice on a C57BL/6 background were generated as previously described (Phaneuf et al., 1996; Yamaguchi et al., 2012). A female $\mathrm{Neu}^{-/-}$mouse was crossed with a male $\mathrm{Hexa}^{-/-}$ mouse to generate doubly heterozygous $\left(\mathrm{Hexa}^{+/-} \mathrm{Neu}^{+/-}\right)$mice. As doubly null $\left(\mathrm{Hexa}^{-/-} \mathrm{Neu}^{-/-}\right)$mice were sterile, mice with either a null $\mathrm{Hexa}^{-/-}$allele $\left(\mathrm{Hexa}^{-/-} \mathrm{Neu3^{+/- }}\right.$ ) or a null $\mathrm{Neu}^{-/-}$allele $\left(\mathrm{Hexa}^{+/-} \mathrm{Neu} 3^{-/-}\right.$) were mated with each other to establish a colony. The mice were bred in a laboratory animal facility at the Izmir Institute of Technology. The mice were housed in groups of five per cage and maintained at a constant temperature with an alternating 12-h light/ dark cycle. Food and water were available ad libitum. All animal experiments were performed in accordance with the Turkish Institute of Animal Health guide for the care and use of laboratory animals. The animal studies were approved by the Institutional Animal Care and Use Committee of the Izmir Institute of Technology. The Hexa and Neu3 genotypes were identified by PCR using genomic DNA extracted from the tails of the mice. The wild-type (WT) and mutant Hexa alleles were determined by PCR using AmpONE Taq DNA polymerase (GeneAll Biotechnology Co. Ltd., Korea) and the primers HexaF (5"-GGCCAGATACAATCATACAG-3"), HexaR (5"-CTGTCCACATACTCTCCCCACAT$3^{\prime \prime}$ ) and PGKR (5"-CACCAAAGAAGGGAGCC GGT-3"). The wild-type primers (HexaF and HexaR) yielded a 425-bp fragment and the mutant primers (HexaF and PGKR) yielded a 216-bp fragment. The wild-type and mutant Neu3 alleles were determined by PCR with Taq DNA polymerase (Invitrogen Life Technologies, USA) and the primers Neu3F (5"-GCTCTACCCCATTCTACATCTCCAGAC-3"), Neu3R (5"-TCGTGCTTTACGGTATCGCCGCTCCCGATT-3"), and NeoR (5"-GTGAGTTCAA
GAGCCA TGTTGCTGATGGTG-3"). The primers Neu3F and Neu3R generated a DNA fragment of 2110 bp derived from the wildtype allele, whereas the primers Neu3F and NeoR generated a DNA fragment of 1689 bp derived from the targeted allele. The combination of the PCRbased procedures for the Hexa and Neu3 alleles allowed unequivocal identification of all four of the possible genotypes.

\subsection{Quantitative gene expression assay by real-time PCR and Western bloting}

The relative expression levels of mRNA for the genes encoding Neu1, Neu3, GM2 activator protein (GM2AP) and $\beta$-hexosaminidase B (HEXB) were determined using LightCycler 480 SYBR Green I Master Mix (Roche, Germany) with the glyceraldehyde-3-phosphate dehydrogenase (GAPDH) gene as an internal control. The total RNA was extracted from brain tissue sections from each genotype $(n=3)$ using TRIzol Reagent (Geneaid, Germany) and $50 \mathrm{ng} / \mu \mathrm{L}$ cDNA was synthesized with a High-Capacity cDNA Reverse Transcription Kit (Applied Biosystems, USA). The real-time PCR method was optimized with $75 \mathrm{ng}$ cDNA in a $20 \mu \mathrm{L}$ reaction mixture containing $0.4 \mu \mathrm{M}$ primer pair and $1 \times$ Roche LightCycler 480 SYBR Green I Master Mix. The optimal PCR conditions were determined to be as follows: 1 cycle of $10 \mathrm{~min}$ at $95^{\circ} \mathrm{C}$, followed by 45 cycles of $20 \mathrm{~s}$ at $95^{\circ} \mathrm{C}, 15 \mathrm{~s}$ at $61^{\circ} \mathrm{C}$, and $22 \mathrm{~s}$ at $72{ }^{\circ} \mathrm{C}$. Readings were taken after each cycle. After a final cycle of $30 \mathrm{~s}$ at $95^{\circ} \mathrm{C}$ and, $10 \mathrm{~s}$ at $60^{\circ} \mathrm{C}$, continuous reading was applied while increasing the temperature to $99^{\circ} \mathrm{C}$ to detect the presence of primer dimers. The comparative threshold (CT) method was used for data analysis. Data are reported as the mean $\pm \mathrm{SE}$. The $p$ values between data sets were determined by one-way-ANOVA analysis using GraphPad. Significance was defined as $p<0.05$. The following primer pairs were used for each gene of interest: Gm2ap, APF (5"-GCTGGCTTCTGGGTCAAGAT-3", APR (5"-GCACTGTGAAGTTGCTCGTG-3"); Hexb, HexBF (5"AGTGCGAGTCCTTCCCTAGT-3"), HexBR (5"-ATCCGGACATCGTTTG GTGT-3"); GAPDH, GapdhF (5"-CCCCTTCATTGACCTCAACTAC-3") and, GapdhR (5"-ATGCATTGCTGACAATCTTGAG-3"); Neu1, Neu1F (5"-TCATCGCCATGAGGAGGTCCA-3") and, Neu1R (5"-AAAGGGAATG CCGCTCACTCCA-3"); Neu3, Neu3F (5"-CTCAGTCAGAGATGAGG ATGCT-3") and, Neu3R (5'-GTGAGACATAGTAGGCATAGGC- 3 '). The total RNA was extracted from the cerebellum and cortex tissues of each genotyped mouse using the RNeasy Mini Kit (Qiagen, Germany) following the manufacturer's instructions. The cDNA was synthesized using an $\mathrm{RT}^{2}$ First Strand Kit (Qiagen, Germany) following the manufacturer's instructions. The relative mRNA expression of 84 key genes involved in programmed cell death was determined using an $\mathrm{RT}^{2}$ Profiler PCR Array (Qiagen, Germany). Quantitative real-time PCR was 
A

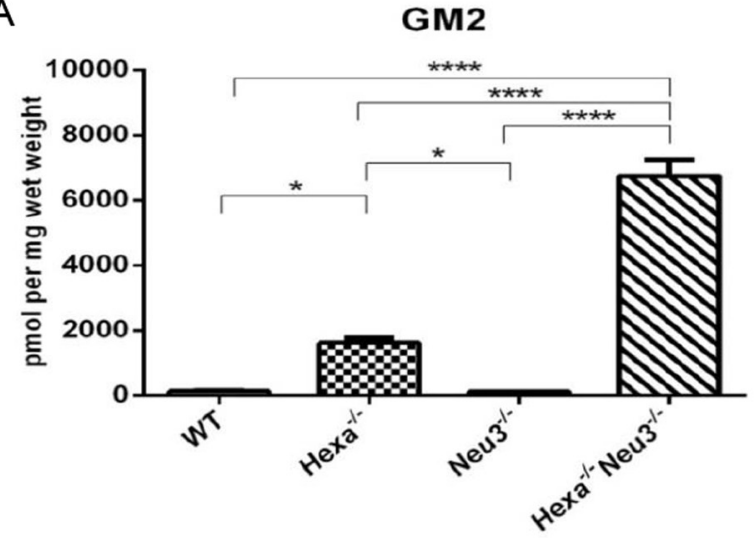

C

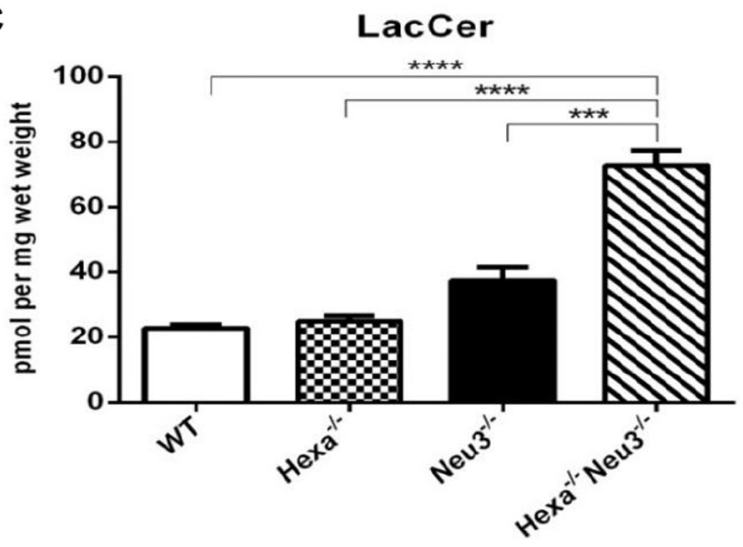

$E$

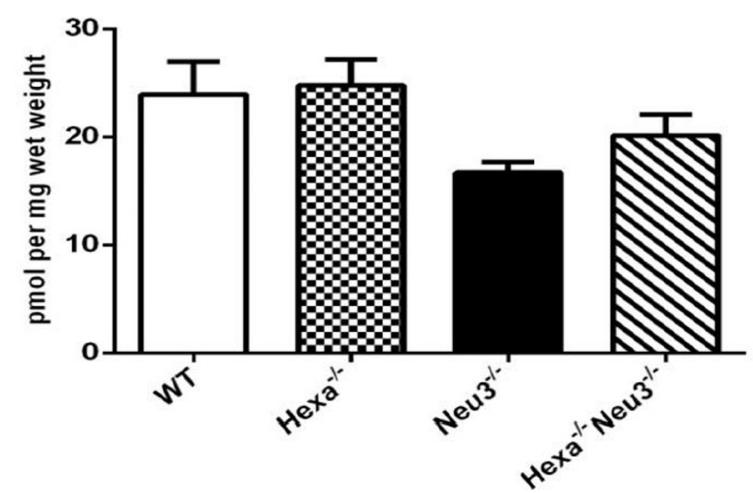

B

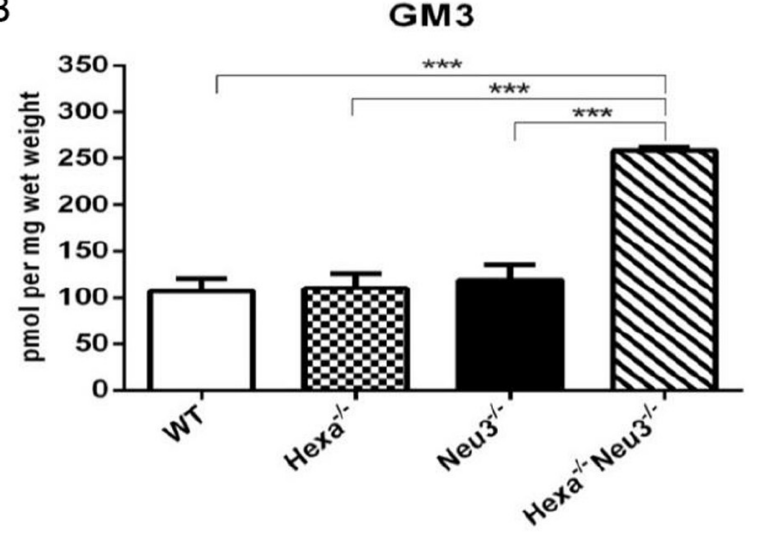

D

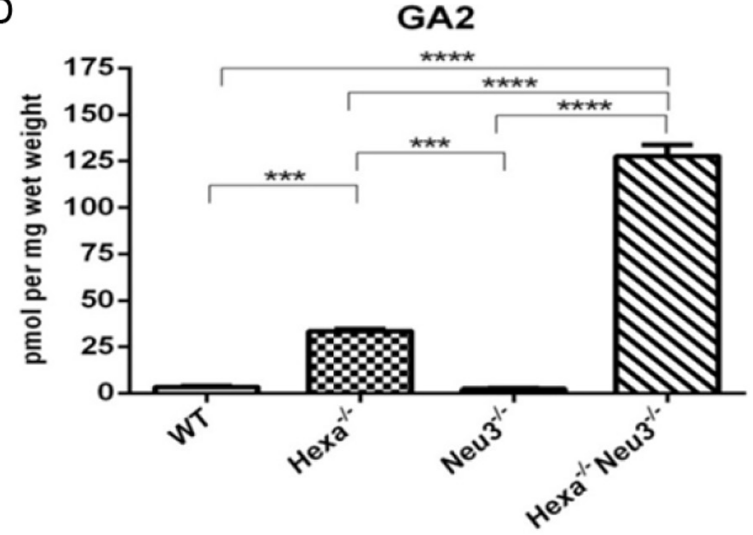

F

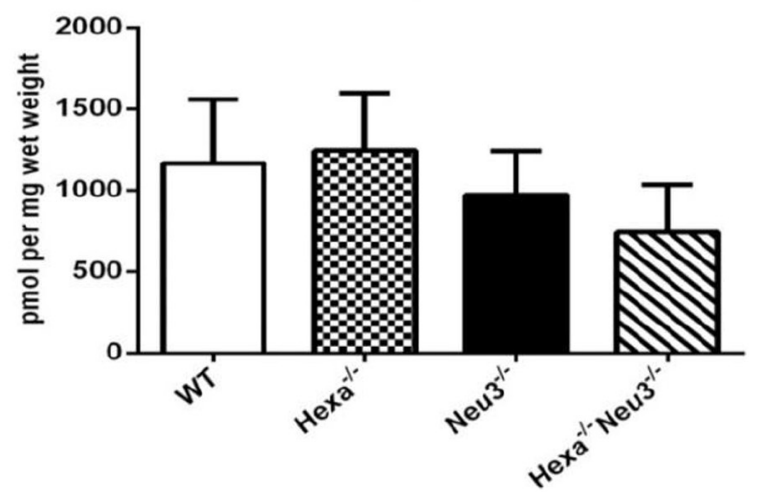

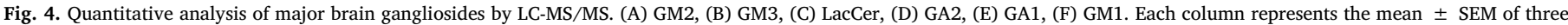
samples. Statistical analysis was performed using one-way ANOVA $\left({ }^{*} p<0.05\right.$, ${ }^{* * *} p<0.001$, and $\left.{ }^{* * * *} p<0.0001\right)$.

performed on a Roche LightCycler 96 instrument using $\mathrm{RT}^{2}$ Real-Time SYBR Green PCR Mastermix (Qiagen, Germany). The expression level of each gene was normalized using the mean expression levels of five housekeeping genes. The data from $\mathrm{Hexa}^{-/-} \mathrm{Neu} 3^{-/-}$mice were compared using the data from $\mathrm{Hexa}^{-/-}$mice (control) as the calibrator. The fold changes in the expression levels of genes were calculated according to the $2^{-\Delta \Delta C T}$ method. Genes that exhibited positive or negative fold changes of $>1.5$ were considered as increased or decreased. For Western Blot analysis, total protein concentration from the lysates was determined using the Bradford protein assay. Equal amount of protein was loaded and separated in 10\% SDS-PAGE, followed by transfer to nitrocellulose membrane (Bio-Rad, USA). The membranes were then incubated with anti-HexB (1:500, Santa Cruz, USA) and antiactin (1:1000, Cell Signalling, USA) antibodies at room temperature for $2 \mathrm{~h}$, followed by incubation with HRP-conjugated secondary antibodies
(Jackson ImmunoResearch Lab, USA). The proteins were visualized by LuminataTM Forte Western HRP Substrate (Millipore, USA) on a digital imaging system (Fusion SL, Vilber). The density of bands was normalized to actin and quantified using NIH ImageJ.

\subsection{Glycosphingolipid (GSL) extraction and high-performance thin layer chromatography (HPTLC)}

GSLs were extracted from tissues (brain, testes, kidneys, liver, lungs, and muscle), separated and chemically stained as described previously (Sandhoff et al., 2002; Marsching et al., 2014) with minor modifications. In brief, the tissues were homogenized over ice, in $3 \mathrm{~mL}$ of methanol and $300 \mu \mathrm{L}$ of distilled water. Subsequently, $1 \mathrm{~mL}$ of methanol and $3 \mathrm{~mL}$ of chloroform were added to the homogenates, and then the supernatants were separated from the pellets. The pellets were re- 
A

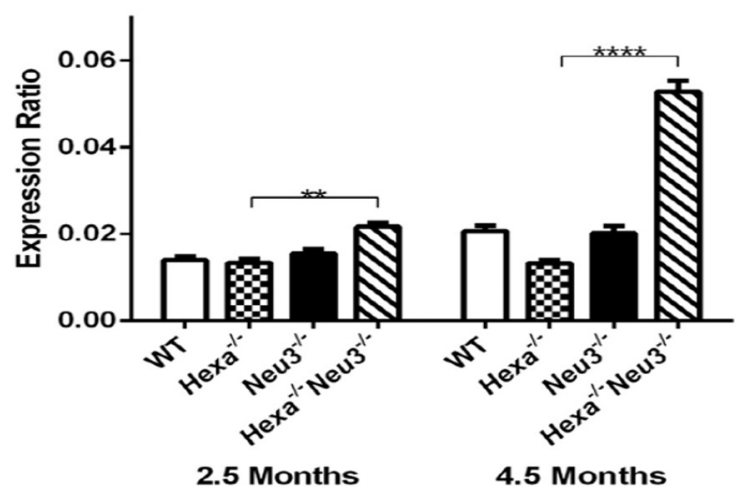

C

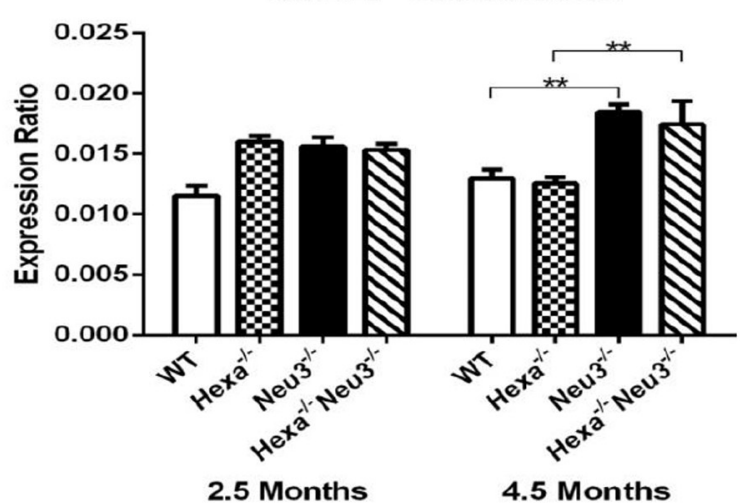

$E$

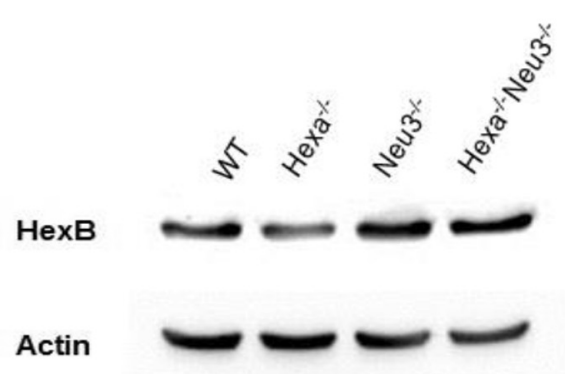

B

HexB Cortex

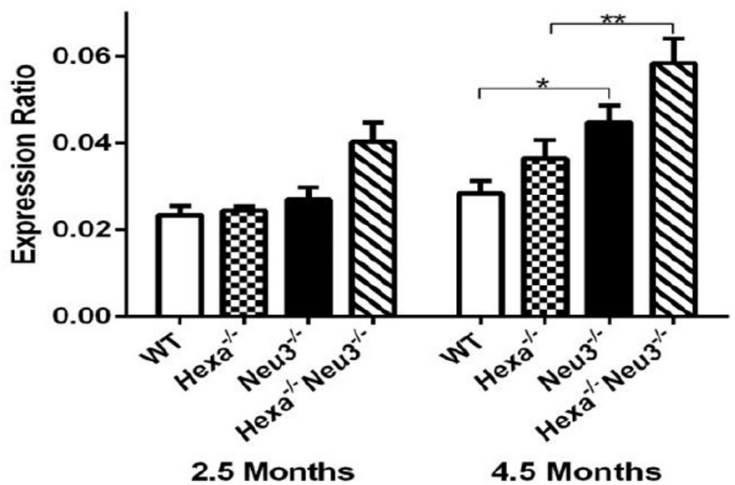

D

GM2AP Cortex

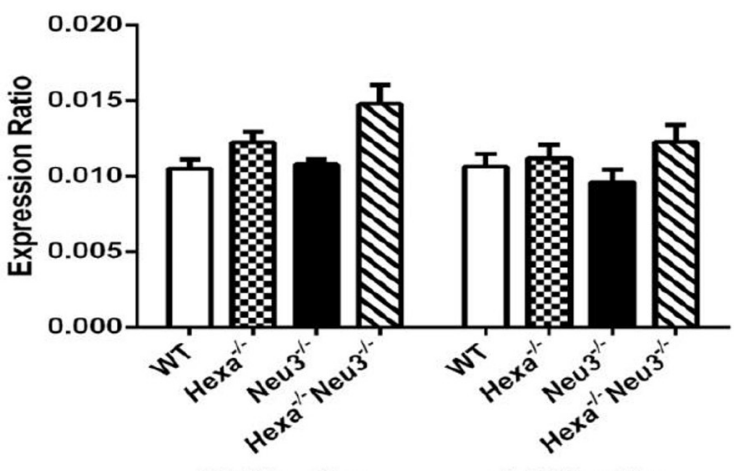

2.5 Months $\quad 4.5$ Months

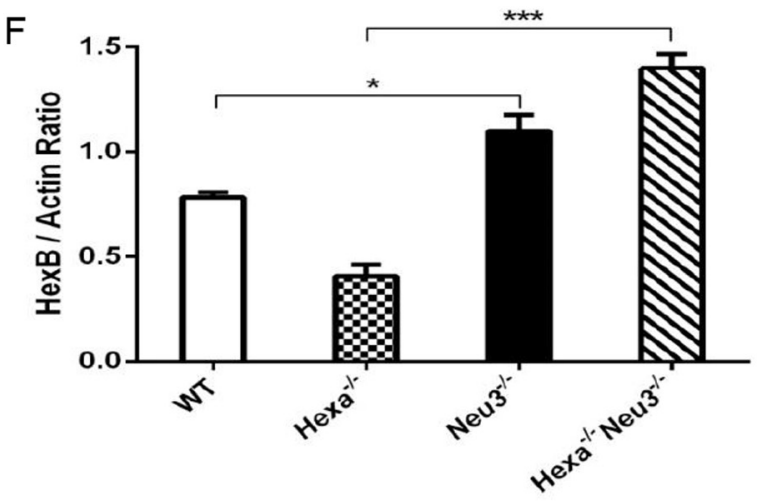

4.5 Months

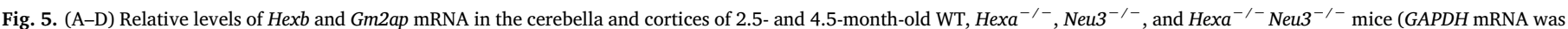

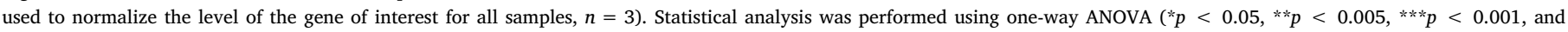

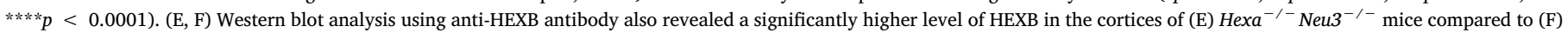
Hexa $^{-\prime-}$ mice.

extracted with solvent mixtures of $\mathrm{CHCl}_{3} / \mathrm{CH}_{3} \mathrm{OH} / \mathrm{H}_{2} \mathrm{O}$, once in ratio of 10:10:1 and once in a ratio of 30:60:8, and all three supernatants were pooled and dried to yield the raw extracts. The raw extracts were desalted on RP-18 columns and separated into neutral and acidic lipids on DEAE A-25 columns. Both fractions were treated with mild base $(0.1 \mathrm{M}$ $\mathrm{KOH}$ in $\mathrm{CH}_{3} \mathrm{OH}$ for $2 \mathrm{~h}$ at $37^{\circ} \mathrm{C}$ ) to hydrolyze ester-based phospholipids. Finally, both fractions were desalted again using RP-18 columns. The dried lipid fractions were taken up in the solvent mixture of $\mathrm{CHCl}_{3}$ / $\mathrm{CH}_{3} \mathrm{OH} / \mathrm{H}_{2} \mathrm{O}$ in a ratio of 10:10:1. The HPTLC lanes were loaded with lipid extracts corresponding to $2 \mathrm{mg}$ tissue wet weight. After pre-development of the loaded HPTLC plates with chloroform/acetone in a ratio of $1: 1$, plates were dried and developed with $\mathrm{CHCl}_{3} / \mathrm{CH}_{3} \mathrm{OH} / 0.2 \%$ aqueous $\mathrm{CaCl}_{2}$, then dried and stained with orcinol to reveal sugarcontaining compounds.

\subsection{GSL extraction and LC-ESI-MS/MS analysis}

GSLs were extracted from tissues as described for the HPTLC analysis, except for the separation step using DEAE A-25 columns. Aliquots corresponding to $1 \mathrm{mg}$ tissue wet weight were mixed with $12 \mathrm{pmol}$ of each of the following internal standards: LacCer(d18:1/14:0), LacCer (d18:1/19:0), LacCer(d18:1/27:0), GA2(d18:1/19:0), GA1(d18:1/ 19:0), GM3(d18:1/19:0), GM2(d18:1/14:0), and GM1a(d18:1/19:0). The standards were synthesized from commercially available lyso-GSLs 
A

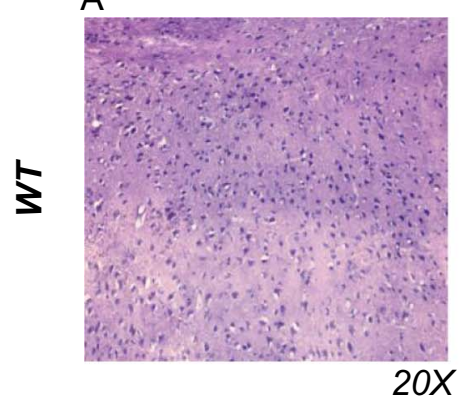

C

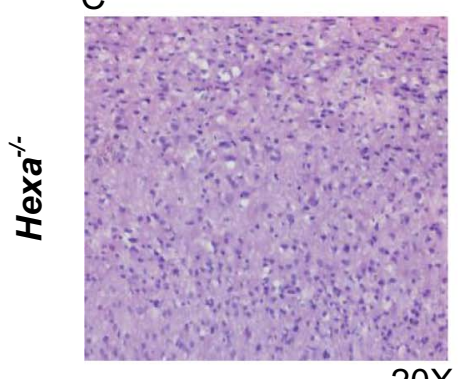

E

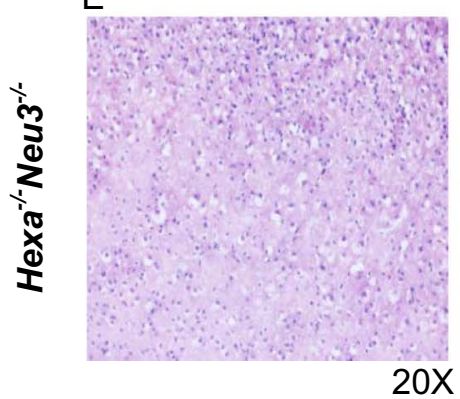

B

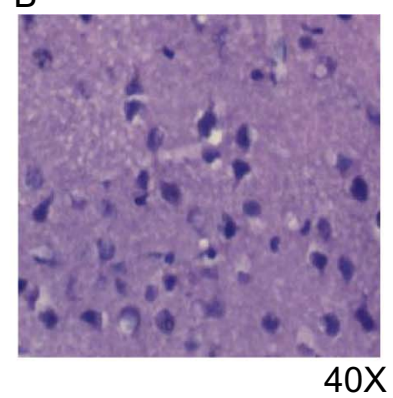

$\mathrm{D}$

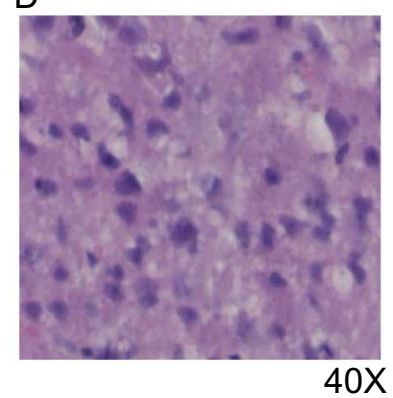

$\mathrm{F}$

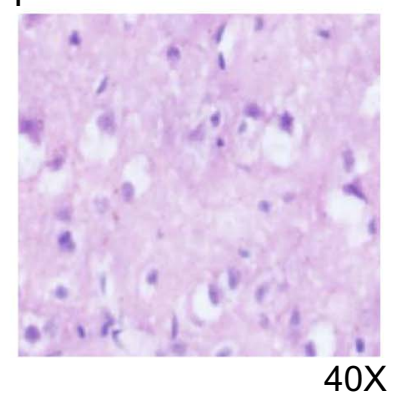

G

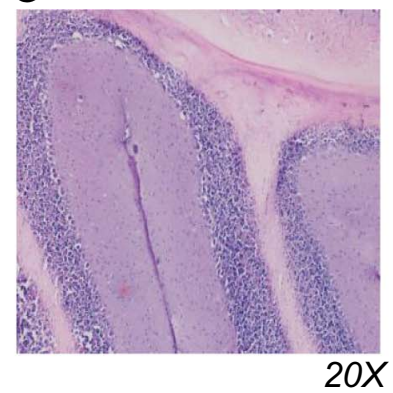

I

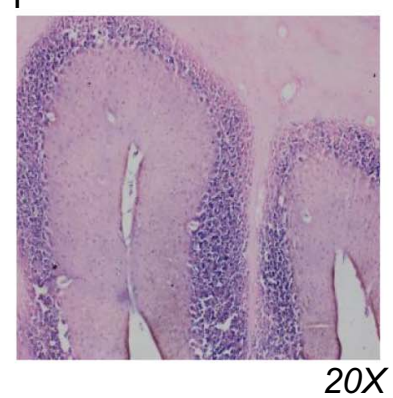

$\mathrm{L}$

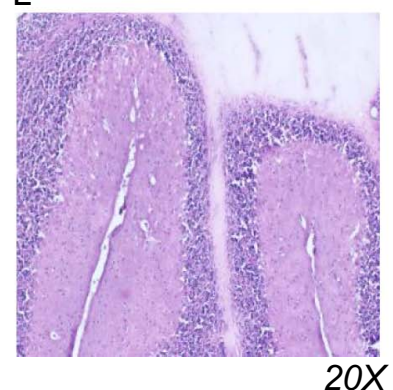

$\mathrm{H}$

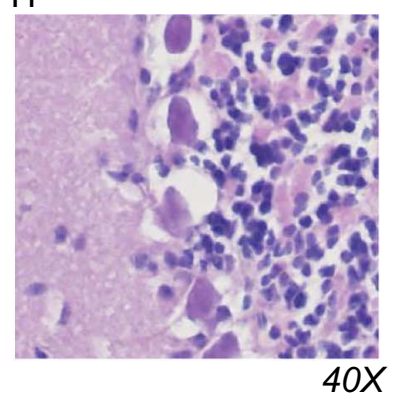

$\mathrm{K}$

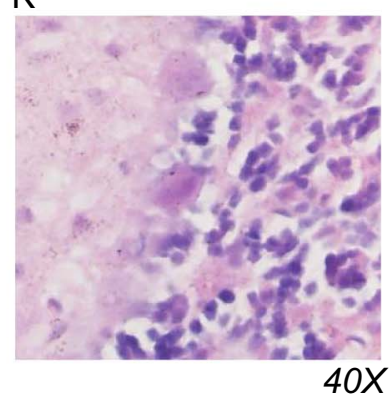

$\mathrm{M}$

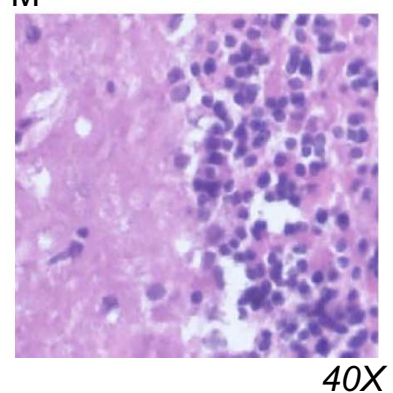

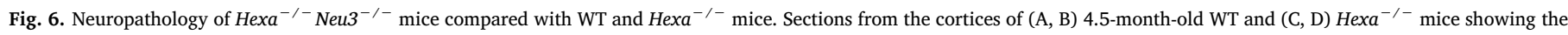

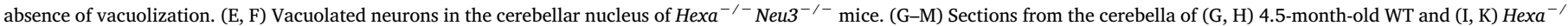
mice, showing the normal Purkinje cell layer that is absent in (L, M) $\mathrm{Hexa}^{-/-} \mathrm{Neu}^{-/-}$mice.
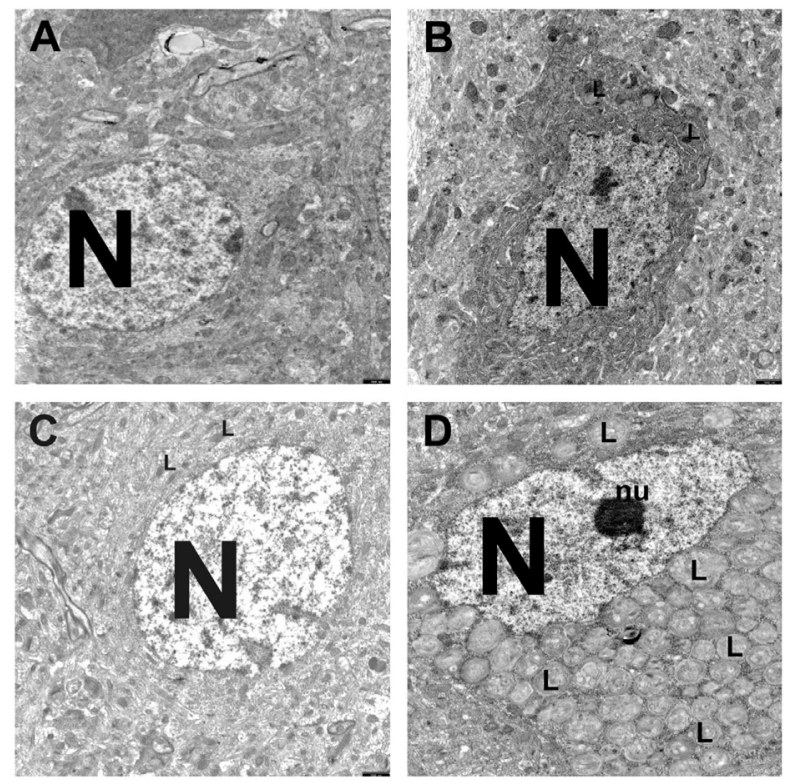

Fig. 7. Transmission electron micrographs of neuronal inclusions in the cortex and increased number of lysosomes. (A) WT, (B) $\mathrm{Hexa}^{-1-}$, (C) $\mathrm{Neu}^{-/-}$, and (D) $\mathrm{Hexa}^{-\prime}$ ${ }^{-} \mathrm{Neu}^{-/-}$mice. N: nucleus; L: lysosomes; nu: nucleolus. and the corresponding activated fatty acids as described previously (Sandhoff et al., 2002), or from commercially available GSLs, that were first converted into the corresponding lyso-GSLs by SCDase treatment according to a literature method (Sandhoff et al., 2002). The samples spiked with the internal standards were dissolved in $60 \%$ aqueous methanol. LC-MS/MS analysis was performed on a Xevo TQ-S tandem mass spectrometer with an ESI-source coupled to an automated Acquity I Class UPLC system using an Acquity UPLC BEH C18 $1.7 \mu \mathrm{m}$ column (50 mm length, $2.1 \mathrm{~mm}$ diameter), all from Waters Corp. The column was equilibrated with solvent system A (methanol/water/formic acid (60:40:0.2 v/v/v), containing $10 \mathrm{mM}$ ammonium formate), and lipids were eluted with an increasing proportion of solvent system B (2-pro$\mathrm{panol} / \mathrm{methanol} /$ water/formic acid (20:79:1:0.2 v/v/v/v) containing $10 \mathrm{mM}$ ammonium formate) at a flow rate of $0.45 \mathrm{~mL} / \mathrm{min}$ (see Table 1 for the gradient used).

Aliquots of $10 \mu \mathrm{L}$ were injected for each run. The GSLs were detected in positive ESI mode using the selected reaction monitoring mode with the transition of the $\left[\mathrm{M}+\mathrm{H}^{+}\right.$molecular ions to the product sphingoid base ion at $m / z 264$ (i.e. (So[d18:1) $\left.+\mathrm{H}-2 \mathrm{H}_{2} \mathrm{O}\right]^{+}$). The following collision energies were used: LacCer, $57 \mathrm{eV}$; GA2, $57 \mathrm{eV}$; GA1, $65 \mathrm{eV}$; GM3, $48 \mathrm{eV}$; GM2, $57 \mathrm{eV}$, and GM1, $65 \mathrm{eV}$. GSLs containing a C18-sphingosine and a C16:0-, C18:0-, C20:0-, C22:0-, C24:1-,or C24:0-acyl chain were monitored. For quantification, the peak areas of the individual lipid species were divided by the respective average internal standard area, multiplied by the amount of this internal standard, and finally divided by the tissue wet weight used. 

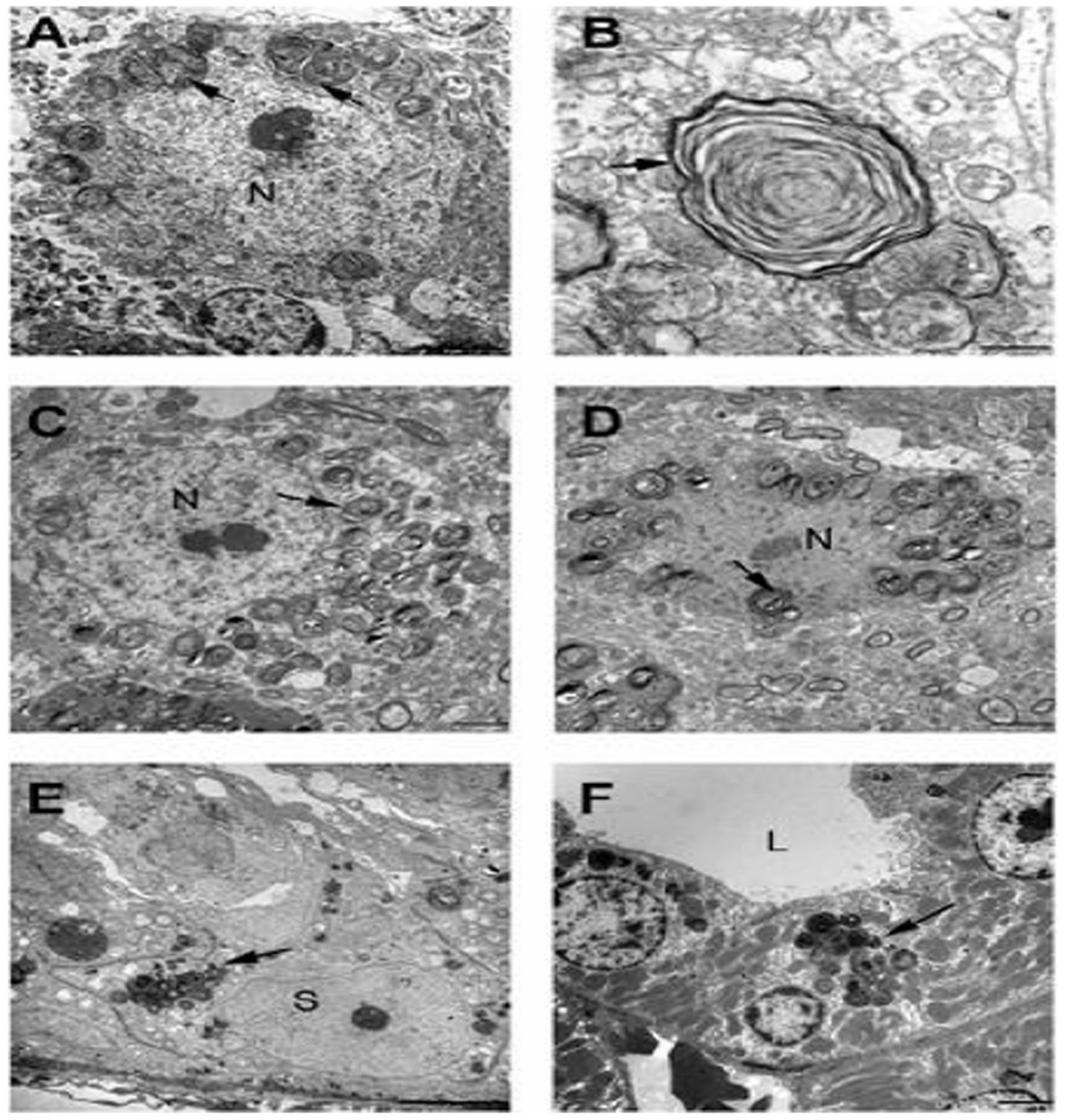

Fig. 8. Transmission electron micrographs showing the accumulation of inclusions in cerebellar and cerebral cortex neurons, testis, and kidney tissues from 4.5-month-old $\mathrm{Hexa}^{-/-} \mathrm{Neu}^{-/-}$mice. (A, B) Representative cerebellar tissue micrographs. (A) Purkinje cells exhibit numerous cytoplasmic inclusions (arrows). (B) At a high magnification, a granular cell shows cytoplasmic inclusions (arrow) with lamellar membrane structure. N, nucleus of the Purkinje cell. Scale bars: A, $5 \mu \mathrm{m}$; B, $500 \mathrm{~nm}$. (C, D) Representative cerebral tissue micrographs. (C) Neurons exhibit numerous cytoplasmic inclusions (arrow). (D) A possible degenerating neuron shows cytoplasmic inclusions (arrow). N, nucleus of the neuron. Scale bars: C and D, $2 \mu \mathrm{m}$. (E) Representative testis tissue micrograph. Cytoplasmic inclusions (arrow) were observed in the Sertoli cell. S, Sertoli cell nucleus. Scale bar, $5 \mu \mathrm{m}$. (F) Representative renal tissue micrograph. A renal tubule cell (distal tubule) near the lumen (L) shows numerous cytoplasmic inclusions (arrow). Scale bar, $2 \mu \mathrm{m}$. These data are representative of two samples.

\subsection{MALDI-TOF MS imaging}

The frozen brains of transgenic and control mice (4.5 month old) were mounted onto a metal chuck with frozen section compound and cut into $10 \mu \mathrm{m}$ cryosections using a Leica cryostat, according to a literature procedure (Fulop et al., 2013). The cryosections were thawmounted onto precooled conductive indium tin oxide (ITO) slides. Before application of the matrix, the ITO slides were desiccated overnight under vacuum at room temperature. A $5 \mathrm{mg} / \mathrm{mL}$ solution of phenylcyano-cinnamamide (Sirius Fine Chemicals (SiChem) GmbH, Bremen) in acetonitrile/water $(90: 10 \mathrm{v} / \mathrm{v})$ was applied to the tissue sections by spray coating using the following parameters of the SunCollect device (SunChrom, Friedrichsdorf, Germany). First, three initial matrix layers were applied using flow rates of $10 \mu \mathrm{L} / \mathrm{min}, 15 \mu \mathrm{L} / \mathrm{min}$, and $20 \mu \mathrm{L} / \mathrm{min}$ followed by six layers at $25 \mu \mathrm{L} / \mathrm{min}$ with a velocity of $1000 \mathrm{~mm} / \mathrm{min}$ to ensure a homogeneous matrix layer on the tissue slides. MALDI imaging mass spectrometry (MALDI-IMS) was performed in negative linear mode in the $m / z$ range of 900-2600 using an Autoflex Speed TOF/TOF with a $2000 \mathrm{~Hz}$ modulated Nd:YAG laser (355 nm) and the FlexImaging 4.0 software (Bruker Daltonics). Prior to analysis, the acquisition method was calibrated using the total ganglioside porcine brain extract (Avanti Polar Lipids, Inc., Alabaster, AL, USA). A total of 200 laser shots were accumulated per raster spot with a laser width of $100 \mu \mathrm{m}$. In addition, baseline subtraction was performed and the images were visualized after total ion current (TIC)-normalization.

\subsection{Histopathology and immunohistochemistry}

Mice of the indicated ages $(n=3)$ were anesthetized and perfused through the heart with $4 \%$ paraformaldehyde (Sigma) in phosphatebuffered saline (PBS; pH 7.4). The brains were removed and placed in the same fixative overnight at $4{ }^{\circ} \mathrm{C}$ and then treated sequentially with
$10 \%, 20 \%$, and $30 \%$ sucrose in PBS overnight at $4{ }^{\circ} \mathrm{C}$. Coronal brain sections were embedded in optimal cutting temperature (OCT) compound (Sigma), sectioned at $10 \mu \mathrm{m}$ thickness, and mounted on HistoBond ${ }^{\circledast}$ microscope slides (Marienfeld) at $-20{ }^{\circ} \mathrm{C}$ using a Leica cryostat. The $10 \mu \mathrm{m}$ coronal brain sections from the mice at the indicated ages were stained with Gill's hematoxylin (Merck, Germany) for $3 \mathrm{~min}$, followed by differentiation in 70\% ethanol:1 $\mathrm{N} \mathrm{HCl}(99: 1, \mathrm{v} / \mathrm{v})$, washing under running tap water, and staining with eosin $\mathrm{Y}$ solution $0.5 \%$ alcoholic (Merck, Germany) for $1 \mathrm{~min}$. The sections were dehydrated with alcohol and xylene. Terminal dUTP nick end-labeling (TUNEL) analysis was performed using the ApopTag Fluorescein in Situ Apoptosis Detection Kit (Millipore) according to the manufacturer's specifications. Briefly, brain sections from each group $(n=4)$ were fixed with paraformaldehyde and ethanol:acetic acid solution (2:1). Sections were incubated with terminal deoxynucleotidyl transferase followed by incubation with an anti-digoxygenin conjugate. Propidium iodide $(0.5 \mu \mathrm{g} / \mathrm{mL})$ was added as a nuclear counterstain. Images were obtained using fluorescent microscope (Olympus) with $\times 10$ magnification. Cerebellum and hippocampus were scanned for positive green fluorescent cells as an indicator of apoptosis. For the immunohistochemical studies, the slides were treated with ice-cold acetone and then, blocked in a humidified chamber with blocking buffer (4\% BSA, 10\% goat serum, and $0.3 \mathrm{M}$ glycine in PBS) $1 \mathrm{~h}$ at room temperature. Anti-GM2 (GM2 ganglioside; KM966) and anti-LAMP1 (lysosomal-associated membrane protein 1; Abcam, USA) were diluted to $1: 500$ in the blocking buffer and applied overnight at $4{ }^{\circ} \mathrm{C}$. The binding of the anti-GM2 and anti-LAMP1 antibodies was visualized using goat anti-human DyLight 488 (Thermo, USA) and goat anti-rabbit Alexa Fluor 568 (Abcam, USA) fluorescent antibodies, respectively. The slides were also blocked in a humidified chamber with $5 \%$ goat serum and $0.3 \%$ Triton X-100 in PBS. Anti-GFAP (glial fibrillary acidic protein; Sigma, Germany) was diluted to 1:200 in blocking buffer and applied 
WT

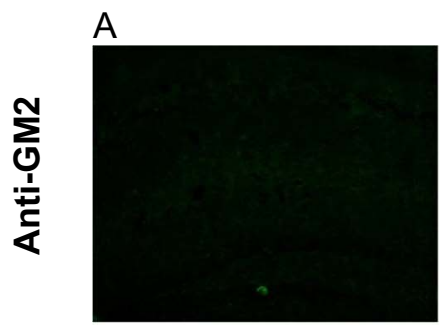

E
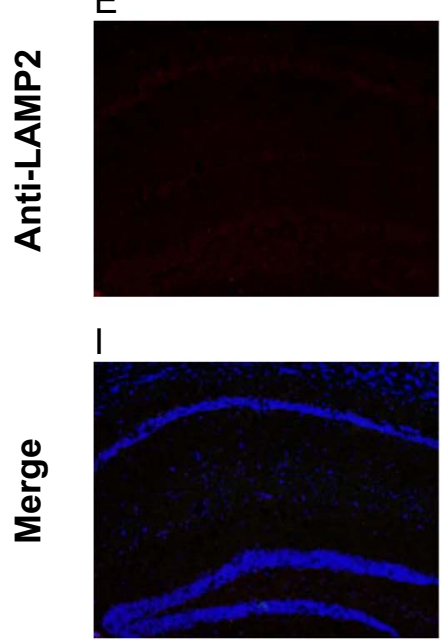

M

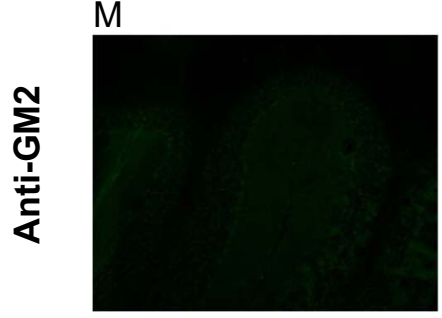

$\mathrm{R}$
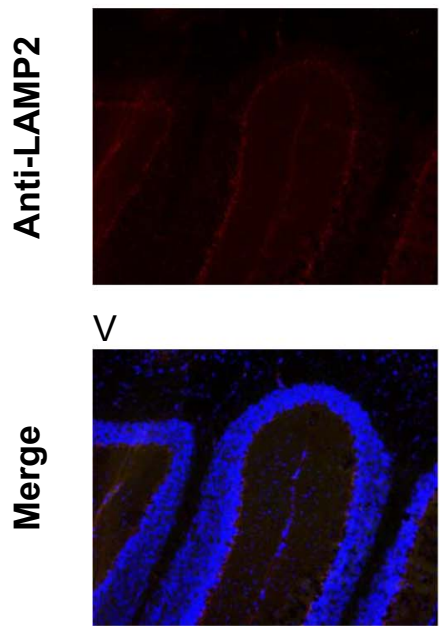

$\mathrm{Hexa}^{-/-}$

B

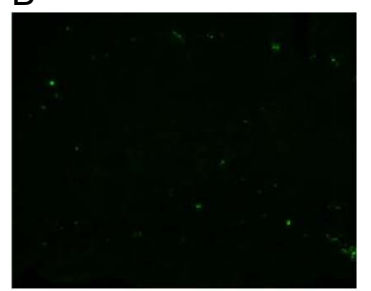

F

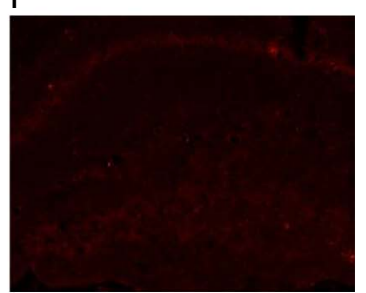

J

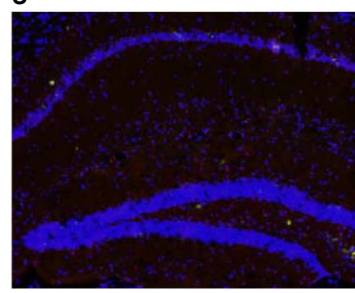

$\mathrm{N}$

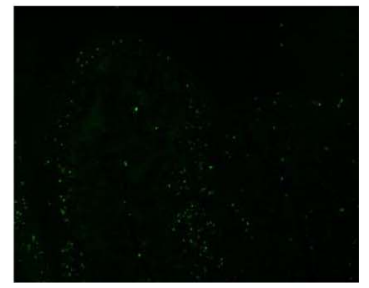

S

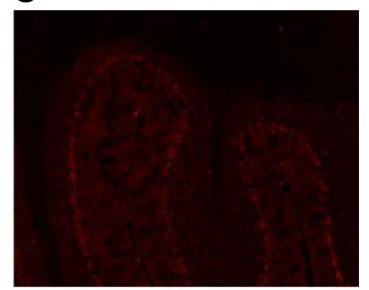

W

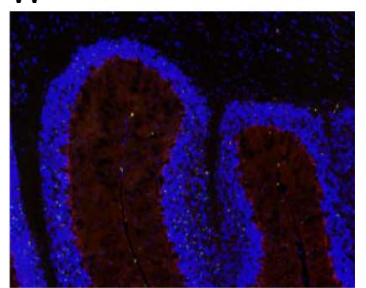

$\mathrm{Neu}^{-/-}$

C

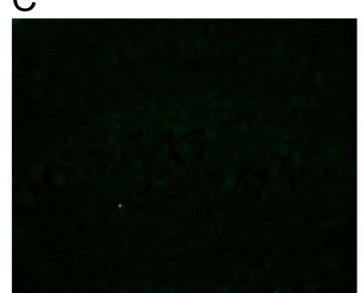

G

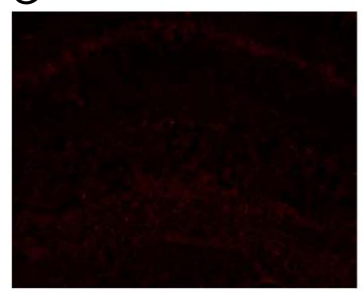

K

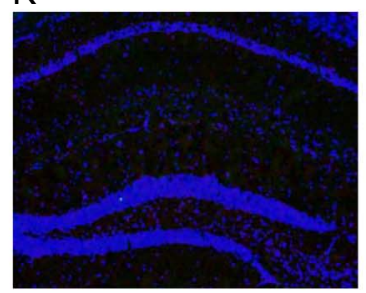

O

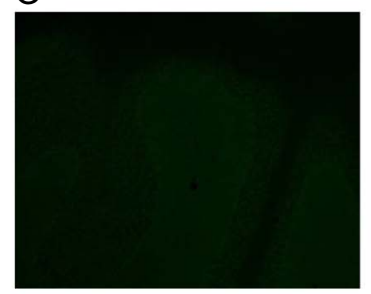

$\mathrm{T}$

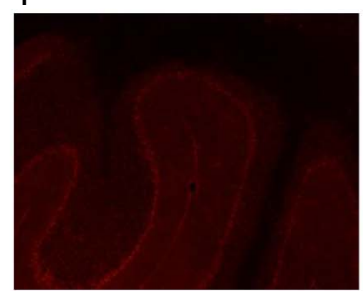

$X$

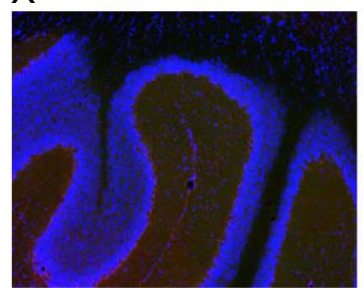

$\mathrm{Hexa}^{-/-} \mathrm{Neu}^{-/-}$

D

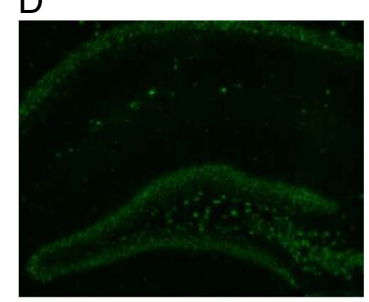

$\mathrm{H}$

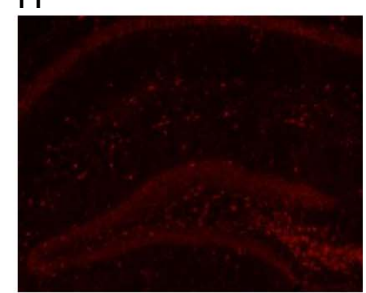

$L$

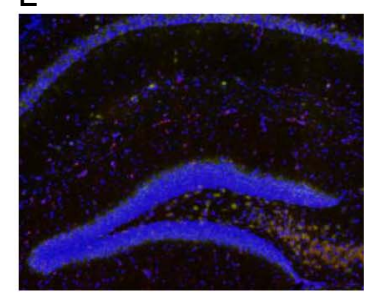

$\mathrm{P}$

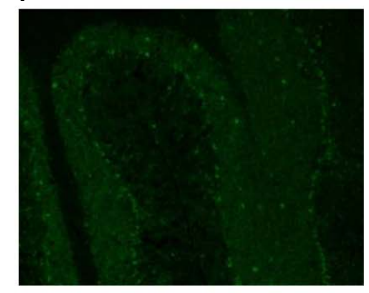

U

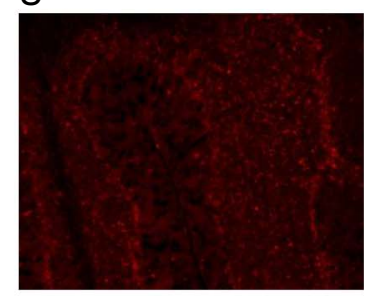

Y

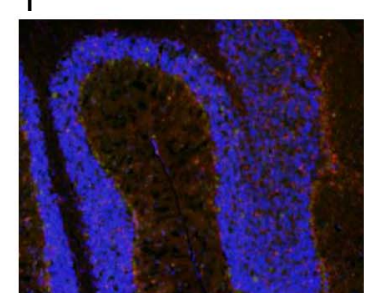

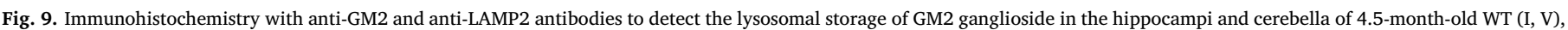
$\mathrm{Hexa}^{-/-}(\mathrm{J}, \mathrm{W}), \mathrm{Neu}^{-/-}(\mathrm{K}, \mathrm{X})$ and $\mathrm{Hexa}^{-/-} \mathrm{Neu} 3^{-/-}$mice (L, Y).

overnight at $4{ }^{\circ} \mathrm{C}$. The binding of GFAP was visualized using goat antimouse Alexa Fluor 488 antibody. The slides were mounted with Fluoroshield mounting medium with DAPI (Abcam, USA) and images were obtained using fluorescence microscopy (Olympus, Germany).

\subsection{Transmission electron microscopy}

Brain (temporal area of the cerebral cortex and cerebellar cortex), testis and kidney tissues were dissected from 4.5-month-old $\mathrm{Hexa}^{-}{ }^{-}$ 
A
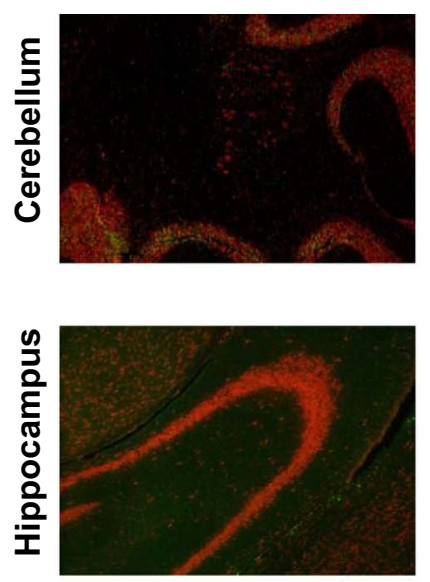

$\operatorname{Hexa}^{-/-}$
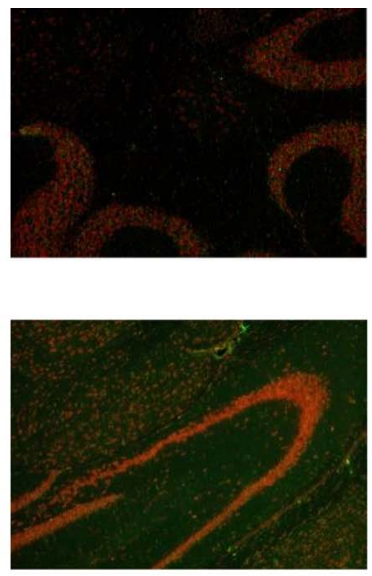

$\mathrm{Neu}^{-1-}$
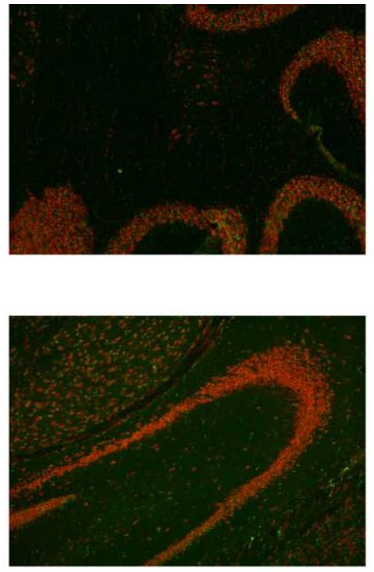

$\mathrm{Hexa}^{-/-} \mathrm{Neu}^{-/-}$
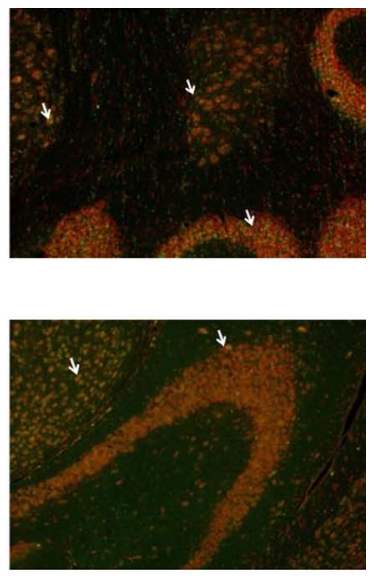

B

\section{Pro-Apoptotic Genes}

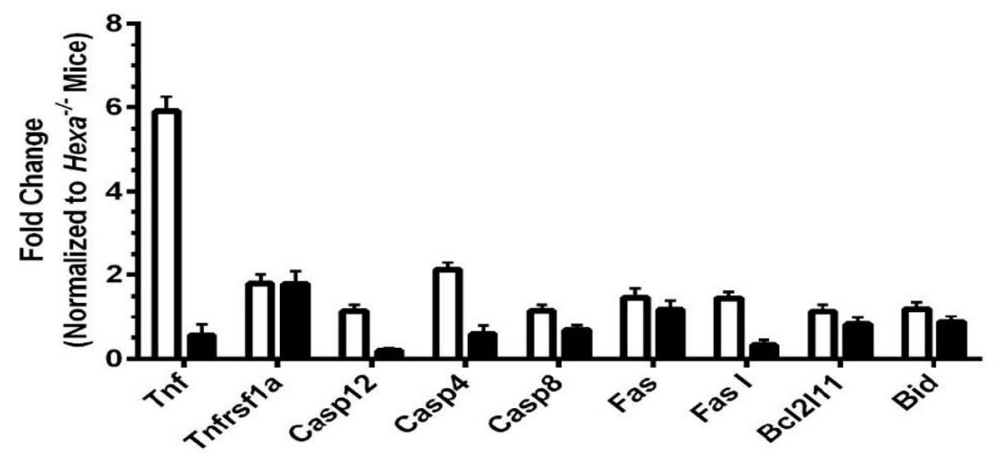

C

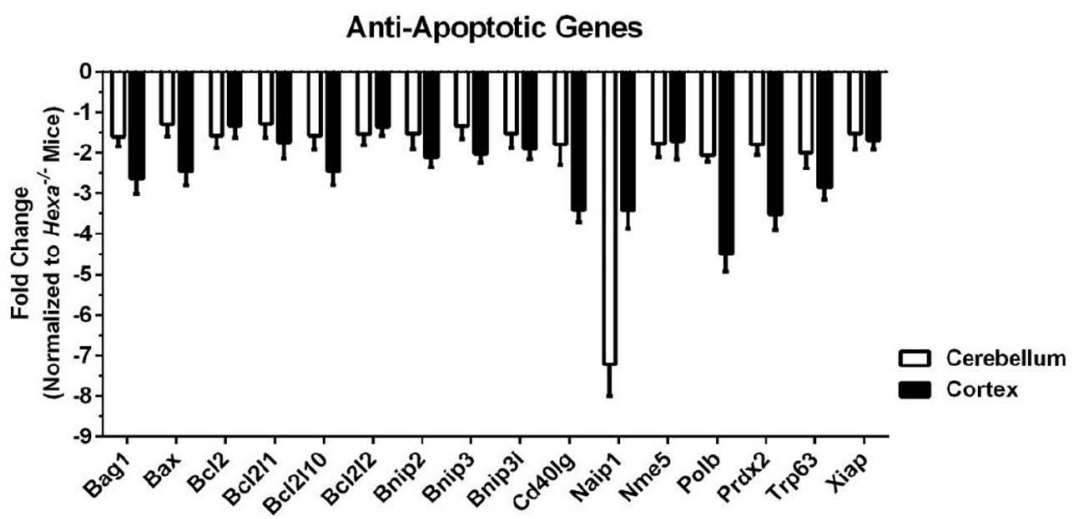

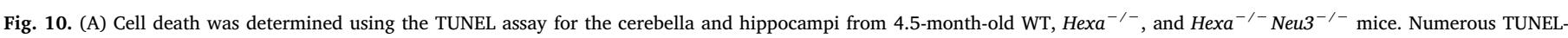

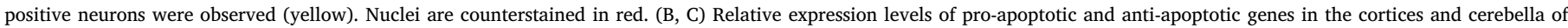

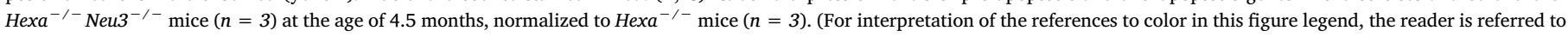
the web version of this article.)

${ }^{-} \mathrm{Neu} 3^{-/-}$mice. The tissue pieces were immersed in $2.5 \%$ glutaraldehyde in $0.1 \mathrm{M}$ phosphate buffer ( $\mathrm{pH} 7.4$ ), post-fixed in 1\% osmium tetroxide in $\mathrm{dH} 2 \mathrm{O}$, dehydrated using a graded acetone series, and embedded in Araldite CY-212. Semi-thin sections ( $1 \mu \mathrm{m}$ thick) were prepared and stained with toluidine blue and then examined under a light microscope to select areas for histological evaluation of the tissues. Ultrathin sections (40-60 nm thick) were prepared, placed on copper grids (200 mesh), and double stained with uranyl acetate and lead citrate prior to examination using Zeiss Libra 120 electron microscope (Carl Zeiss Microscopy GmbH, Germany).

\subsection{Footprint analysis}

WT $(n=3), \mathrm{Hexa}^{-/-}(n=3), \mathrm{Neu}^{-/-}(n=3)$, and Hexa $\mathrm{H}^{-/}$ ${ }^{-} \mathrm{Neu}^{-/-}(n=3)$ mice at the age of 4.5 months were subjected to the footprint test. The fore and hind paws of the WT, $\mathrm{Hexa}^{-/-}, \mathrm{Neu}^{-/-}$, and $\mathrm{Hexa}^{-/-} \mathrm{Neu} 3^{-/-}$mice were painted with nontoxic ink. The animals were then allowed to walk along a runway $(50 \mathrm{~cm}$ long, and $10 \mathrm{~cm}$ wide (with $10 \mathrm{~cm}$ high walls) into an enclosed box on white paper. Their walking patterns were recorded using a scanner (HP). To avoid possible confounding effects in gait abilities, a separate set of animals were used. 

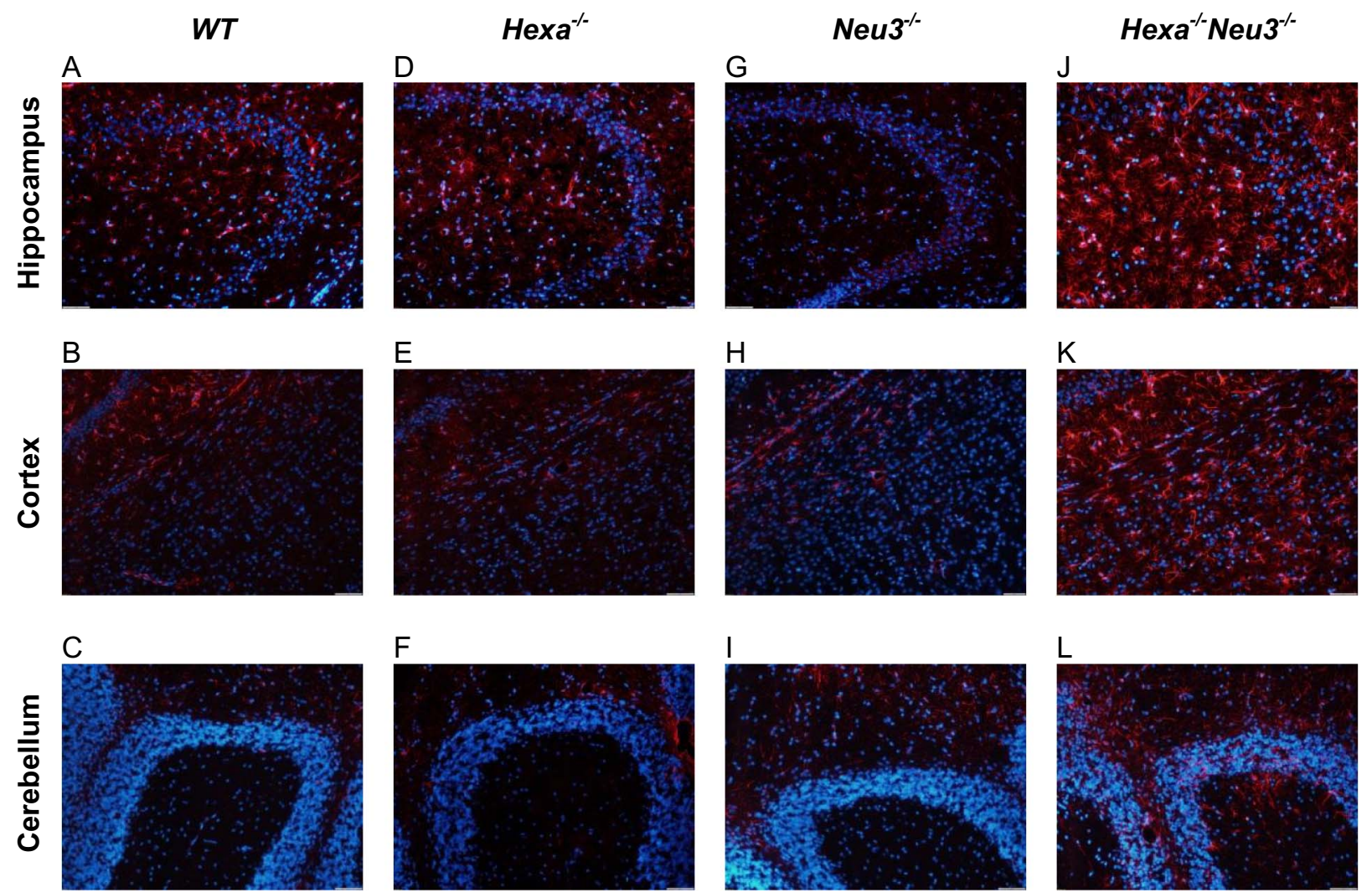

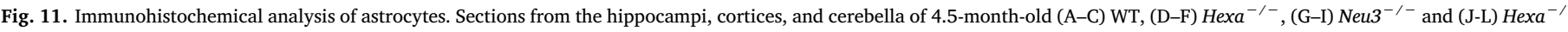
${ }^{-} \mathrm{Neu}^{-/-}$mice were immunostained with GFAP to detect reactive astrogliosis. These data are representative of three samples.

\subsection{Rotarod test}

WT $(n=8), \mathrm{Hexa}^{-/-}(n=7), \mathrm{Neu}^{-/-}(n=10)$, and Hexa ${ }^{-\prime}$ ${ }^{-} \mathrm{Neu} 3^{-1-}(n=11)$ mice at the age of 2.5 months; WT $(n=7)$, $\mathrm{Hexa}^{-1-}(n=6), \mathrm{Neu}^{-/-}(n=5)$, and Hexa ${ }^{-1-} \mathrm{Neu}^{-/-}(n=2)$ mice at the age of 3.5 months; and WT $(n=19)$, Hexa $^{-1-}(n=14)$, $\mathrm{Neu}^{-/-}(n=17)$, and $\mathrm{Hexa}^{-/-} \mathrm{Neu}^{-/-}(n=16)$ mice at the age 4.5 months were subjected to a rotarod test to evaluate motor coordination and balance. The mice were first trained to walk on the rotarod at a constant rotation speed of $5 \mathrm{rpm}$ for a maximum of $5 \mathrm{~min}$. The testing session was performed with the rotarod rotating at an increasing speed ( 4 to $40 \mathrm{rpm}$ over $5 \mathrm{~min}$ ). The latency to fall was recorded using Sedacom version 2.0 (Harvard Apparatus). The mice were required to perform three trials for each test and time point, with a rest period of $15 \mathrm{~min}$ between trials. In the analysis, the mean latency to fall of three trials was used.

\section{Results}

\subsection{Generation of a Hexa $a^{-/-} \mathrm{Neu} 3^{-/-}$mouse strain}

The $\mathrm{Hexa}^{-/-}$and $\mathrm{Neu}^{-/-}$mice were generated previously (Phaneuf et al., 1996; Yamaguchi et al., 2012) and interbred to produce the $\mathrm{Hexa}^{-/-} \mathrm{Neu}^{-/-}$double-knockout mice. The mice were bred as heterozygous to produce WT, $\mathrm{Hexa}^{-/-} \mathrm{Neu} 3^{+/+}$, and $\mathrm{Hexa}^{+/+} \mathrm{Neu}^{-/}$ - mice along with the Hexa ${ }^{-/-} \mathrm{Neu} 3^{-/-}$mice. The Hexa gene, encodes the $\alpha$ subunit of $\beta$-hexosaminidase A (HEXA) and the Neu3 gene, encodes plasma-membrane-associated sialidase (NEU3). Based on previous data suggesting the existence of a glycosphingolipid degradation bypass pathway as shown in Fig. 1A, we predicted that the deletion of both of these enzymes would completely block the degradation of GM2 ganglioside in mice (Yamanaka et al., 1994; Sango et al., 1995; Phaneuf et al., 1996). To elucidate the identity of the sialidase(s) responsible for phenotypic rescue in $\mathrm{Hexa}^{-/-}$mice, we first assessed the expression levels of all of the sialidase genes (Neu1-Neu4) that might participate in a metabolic bypass pathway. We used quantitative RT-PCR to analyze the changes in the expression levels of the sialidase genes from different sections of the brains of WT and Hexa ${ }^{-1-}$ mice. In this analysis, Neu2 and Neu4 showed no differences in their relative expression levels between WT and $\mathrm{Hexa}^{-/-}$mice (data not shown), while the expression levels of Neu1 and Neu3 were increased significantly in the cerebellum, cortex, hippocampus, and thalamus of $\mathrm{Hexa}^{-1-}$ mice compared to WT mice. The results indicated that the Neu1 gene is by far the most induced sialidase gene in the mouse brain (Fig. 1B). NEU1 is also the sialidase most likely to account for the metabolic bypass seen in $\mathrm{Hexa}^{-\prime}$ - mice, because it is involved in the NEU1/cathepsin A/ $\beta$-galactosidase complex found in the lysosomes. Additionally, an earlier study demonstrated that the lysosomal storage of GM2 ganglioside in human Tay-Sachs neuroglia cells and skin fibroblasts could be overcome by overexpressing human NEU1/cathepsin A, suggesting that at least the first response of the metabolic bypass is related to an increase in sialidase expression (Igdoura et al., 1999). Interestingly, the mRNA expression of Neu3, also increased in response to a block in GM2 ganglioside degradation (Fig. 1C). Furthermore, the expression of Neu3 was low in normal mice but was induced by 1.5-2.0 fold in whole brain sections of $\mathrm{Hexa}^{-/-}$mice. Based on the observed expression patterns of the sialidases, we postulated that the induction of Neu3, either independently or in concert with Neu1, underscored the metabolic bypass, preventing the accumulation of GM2 that was expected to occur in $\mathrm{Hexa}^{-/-}$mice.

\subsection{A severe and progressive phenotype in $\mathrm{Hexa}^{-/-} \mathrm{Neu}^{-/-}$mice}

Viable $\mathrm{Hexa}^{-/-} \mathrm{Neu}^{-/-}$mice were obtained at the frequency expected by Mendelian considerations, indicating the absence of embryonic lethality. At birth, no differences could be observed between 


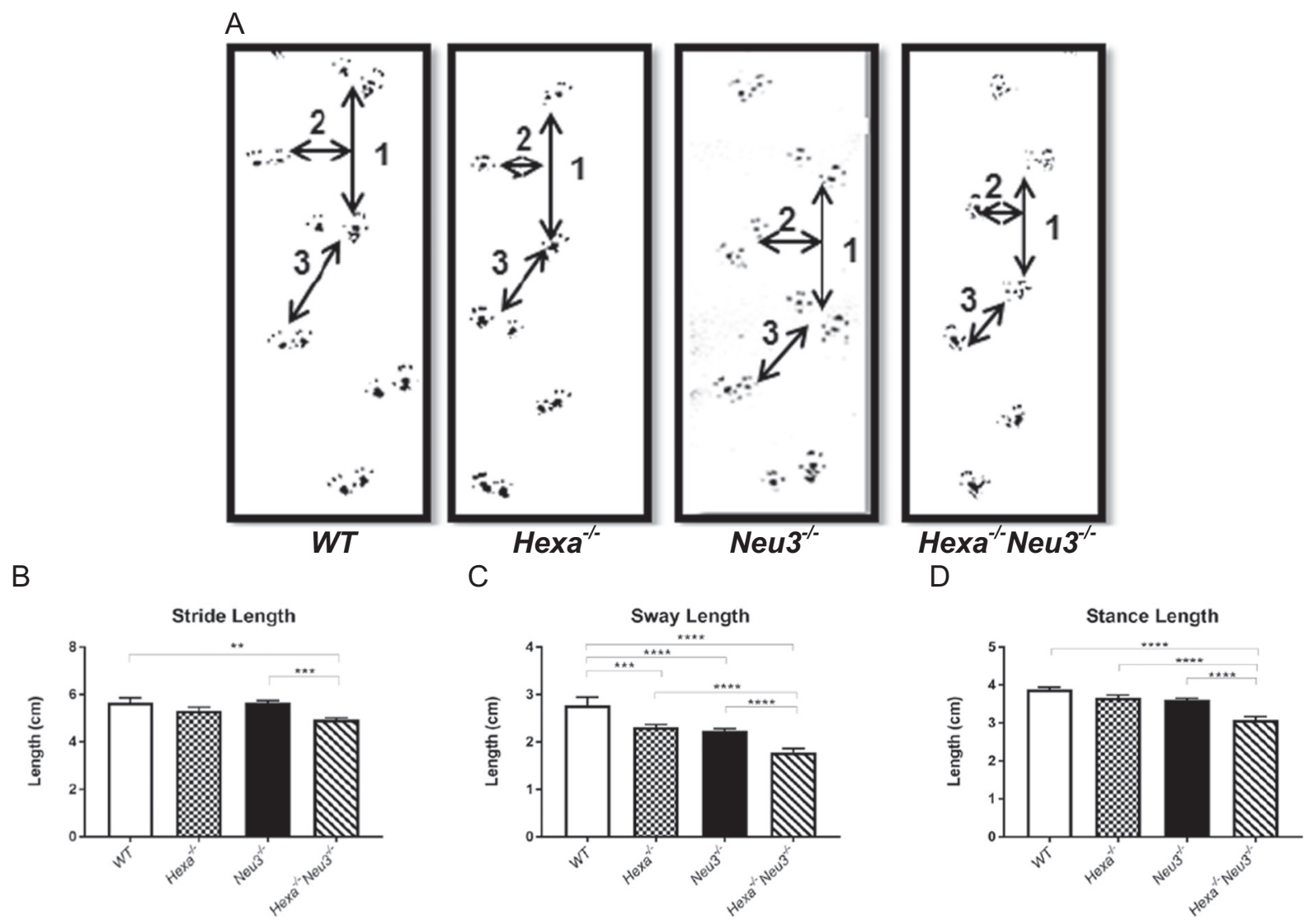

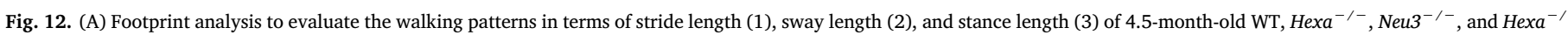

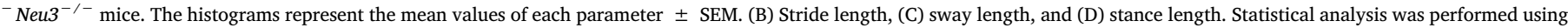
one-way ANOVA $\left({ }^{*} p<0.05,{ }^{* *} p<0.025\right.$, ${ }^{* * *} p<0.001$, and $\left.{ }^{* * * *} p<0.0001\right)$.

WT, $\mathrm{Hexa}^{-/-}, \mathrm{Neu}^{-/-}$, and $\mathrm{Hexa}^{-/-} \mathrm{Neu}^{-/-}$mice. However, growth delay became apparent in $\mathrm{Hexa}^{-/-} \mathrm{Neu}^{-/-}$mice after the age 2.5-months. Hexa ${ }^{-/-} \mathrm{Neu}^{-/-}$mice developed body weight similar to WT, $\mathrm{Hexa}^{-/-}$, and $\mathrm{Neu}^{-{ }^{--}}$mice until 14 to 15 weeks of age, but then body weight declined in contrast to the other three mouse lines. At 20 weeks of age $\mathrm{Hexa}^{-/-} \mathrm{Neu}^{-/-}$reached the same weight again, which they had at 8 weeks (Fig. 2A, B, C). Furthermore, the $\mathrm{Hexa}^{-\prime}$ ${ }^{-} \mathrm{Neu}^{-/-}$mice were approximately $15-20 \%$ smaller than the Hexa ${ }^{-/}$ - mice (Fig. 2D), while the radiographic analysis revealed a hunched posture in the $\mathrm{Hexa}^{-/-} \mathrm{Neu} 3^{-/-}$mice similar to previously described the mice lacking both subunits of lysosomal beta-hexosaminidase (Fig. 2E) (Sango et al., 1995). The locomotor activities of the $\mathrm{Hexa}^{-\prime}$

${ }^{-} \mathrm{Neu} 3^{-/-}$mice gradually decreased after birth, and, ataxia and tremors later developed. By four months after birth, they had started to exhibit gait disturbance with severe shaking. The majority of the $\mathrm{Hexa}^{-/-} \mathrm{Neu}^{-/-}$mice died by the age of 3-4 months and only a few lived to five months. At the age of 4.5 months, the brains of the Hexa ${ }^{-1}$

${ }^{-} \mathrm{Neu} 3^{-/-}$mice were morphologically intact but significantly heavier than those of their single-knockout and WT littermates (data not shown), suggesting severe lipid accumulation in the brain. In contrast, the brains of the $\mathrm{Hexa}^{-/-} \mathrm{Neu} 3^{-/-}$mice showed only a slight increase in size (Fig. 2F). The single-knockout mice survived longer than 1.5 years and exhibited no neurological abnormalities in comparison to the double-knockout mice. Furthermore, the heterozygous mice $\left(\mathrm{Hexa}^{+/-} \mathrm{Neu}^{-/-}\right.$or $\mathrm{Hexa}^{-/-} \mathrm{Neu}^{+/-}$) exhibited no obvious abnormalities. Both male and female $\mathrm{Hexa}^{-/-} \mathrm{Neu}^{-/-}$mice were sterile and never produced offspring when crossed with WT mice on either C57BL/6 or $129 /$ sv backgrounds.
3.3. Abnormal accumulation of GM2 ganglioside observed in the brain and visceral organs

As shown in Fig. 3, HPTLC analysis of the acidic and neutral glycolipids was performed for samples of the brains ( 4.5 months of age) and visceral organs (kidneys, lungs, liver, muscle, and testes; 2.5 months of age) of $\mathrm{Hexa}^{-/-} \mathrm{Neu}^{-/-}$mice (Supplementary Materials S3-S7), which revealed a severe block in GM2 degradation. The abnormal accumulation of otherwise minor acidic gangliosides (GM2 and GM3) was observed in the brain and other tissues of $\mathrm{Hexa}^{-1}$ ${ }^{-} \mathrm{Neu} 3^{-1-}$ mice. The accumulation of GM2 was especially severe. Slightly higher neutral glycosphingolipid (GA2) levels were detected only in the $\mathrm{Hexa}^{-/-} \mathrm{Neu} 3^{-/-}$mice. Mass spectrometric analysis revealed the accumulation of GM2 (Fig. 4A) and GM3 (Fig.4B) as well as lactosylceramide (Fig. 4C) and GA2 (Fig. 4D), but not GA1 (Fig. 4E) or GM1 (Fig. 4F) in the brain glycosphingolipid extracts of the Hexa-' ${ }^{-} \mathrm{Neu} 3^{-1-}$ mice. However, the slightly higher level of LacCer and the lower level of GA1 in $\mathrm{Neu} 3^{-/-}$mice was not significant compared to $\mathrm{Hexa}^{-1-}$ and WT mice, respectively (Fig. 4C, E).

The analysis of sagittal mouse brain sections by MALDI-IMS confirmed the massive accumulation of GM2, in the whole brain, and especially in the cerebellum, hippocampus, and cortex, whereas the minor accumulation of GA2 was mainly concentrated in the cerebellum (Supplementary Material S1).

\subsection{Hexa ${ }^{-/-} \mathrm{Neu}^{-/-}$mice exhibit increased expression levels of HEXA associated proteins}

Significantly higher levels of Hexb mRNA were observed in the cerebellum of $\mathrm{Hexa}^{-/-} \mathrm{Neu}^{-/-}$mice (4.5 months old) compared to $\mathrm{Hexa}^{-/-}$(Fig. 5A). In addition, significantly higher levels of Hexb 
A

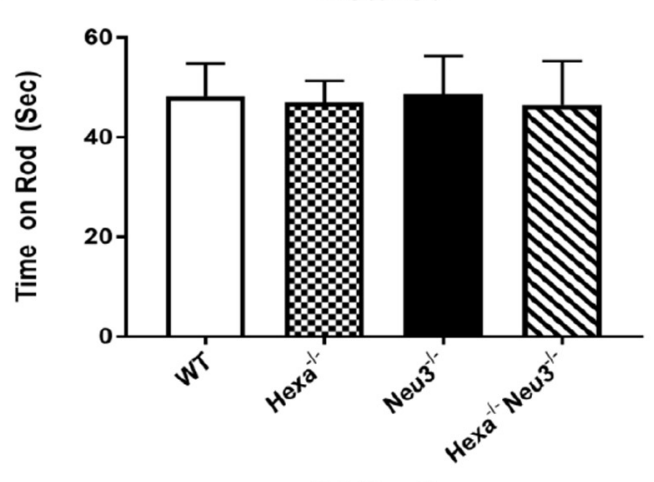

2.5 Months

C

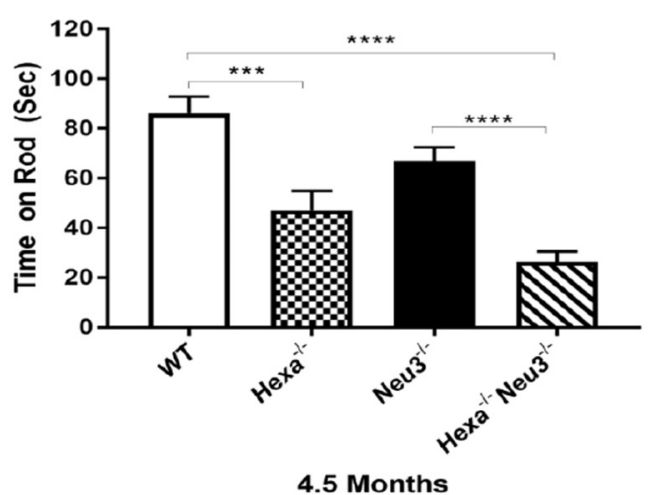

B

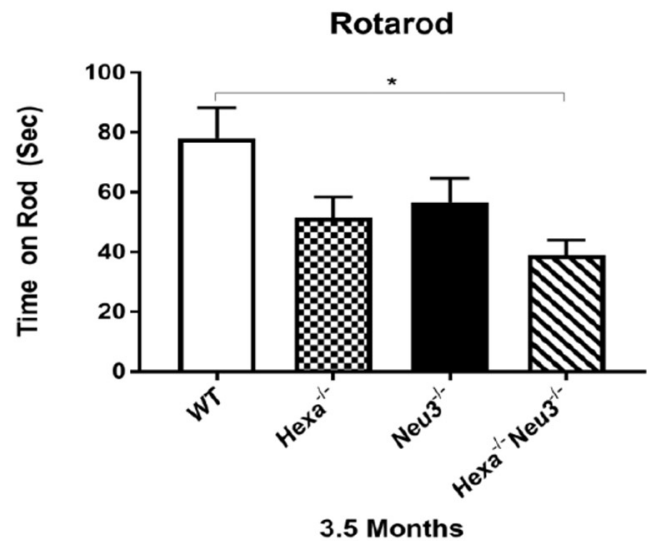

Rotarod

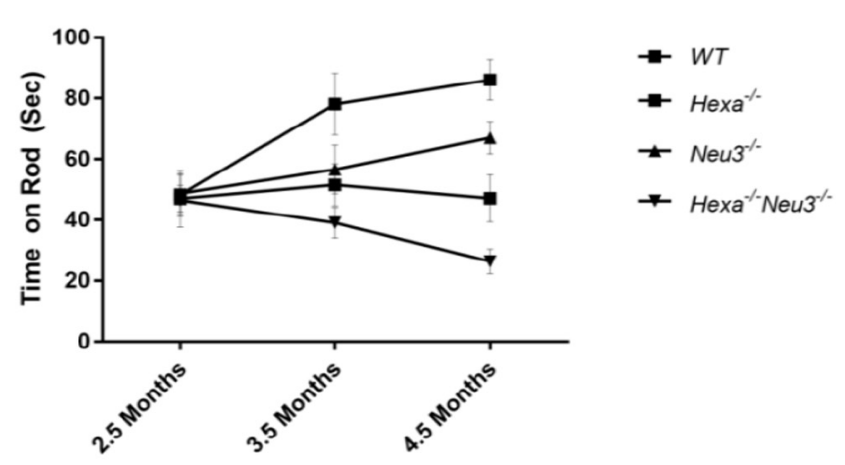

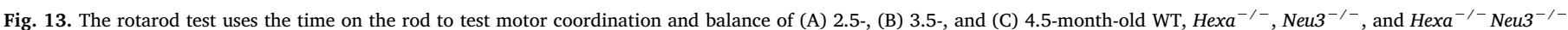

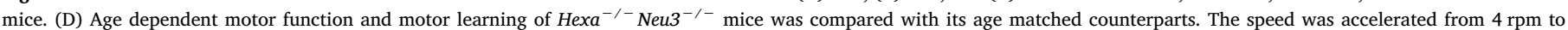

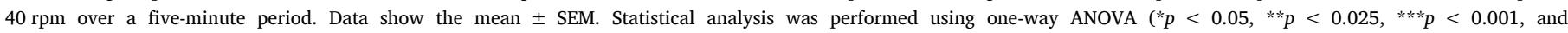
$* * * * p<0.0001)$.

mRNA (Fig. 5B), and its coding protein (Fig. 5E, F) were observed in the cortex of $\mathrm{Hexa}^{-/-} \mathrm{Neu} 3^{-/-}$and $\mathrm{Neu} 3^{-/-}$mice compared to $\mathrm{Hexa}{ }^{-/-}$ and WT mice, respectively. However, the expression level of Gm2ap mRNA was significantly higher only in the cerebellum of $\mathrm{Hexa}^{-/}$ ${ }^{-} \mathrm{Neu} 3^{-/-}$and $\mathrm{Neu} 3^{-/-}$mice (4.5 months old) compared to Hexa ${ }^{-/-}$ and WT mice, respectively (Fig. 5C, D).

\subsection{Hexa ${ }^{-/-} \mathrm{Neu}^{-/-}$mice recapitulated key pathological features of human Tay-Sachs disease}

Histological evaluation of the brains of the $\mathrm{Hexa}^{-/-} \mathrm{Neu}^{-/-}$mice revealed striking vacuolization. For example, the Purkinje cells were specifically affected in the cerebellum (Fig. 6L, M). Light microscopy also revealed cytoplasmic inclusions in the Purkinje cells (Supplementary Material S2A), and neurons (Supplementary Material S2B). The vacuolated monocytes (Supplementary Material S2E) were also observed in the peripheral blood. Electron microscopic analysis demonstrated an abnormal increase in lysosomes in $\mathrm{Hexa}^{-/-} \mathrm{Neu}^{-/-}$mice, which is a prominent morphological marker of distressed neurons that is associated with neurodegenerative diseases (Fig. 7A, D). We also observed membranous cytoplasmic bodies that appeared as concentric ring-like structures in the neuronal lysosomes, like those reported in human Tay-Sachs patients (Fig. 8A, D). The inclusions of many small vesicles and complex lamellar structures observed in the kidney and testis samples could be the cause of urinary retention and infertility in $\mathrm{Hexa}^{-1-} \mathrm{Neu}^{-1-}$ mice (Fig. 8E, F). Immunohistochemical staining with anti-GM2 and anti-LAMP1 antibodies demonstrated the accumulation of GM2 in the brains of $\mathrm{Hexa}^{-/-} \mathrm{Neu}^{-/-}$mice, especially in cerebellum and hippocampus (Fig. 9). Terminal deoxynucleotidyl transferase (TdT) dUTP nick-end labeling (TUNEL) assays showed elevated levels of cell death in the cerebella and hippocampi of $\mathrm{Hexa}^{-}$ ${ }^{-} \mathrm{Neu}^{-/-}$mice compared to the WT and $\mathrm{Hexa}^{-1-}$ mice (Fig. 10A). To verify the increased levels of apoptosis in the cortex and cerebellum, the RNA levels of 84 different pro-apoptotic (Fig. 10B) and anti-apoptotic (Fig. 10C), genes were analyzed. Among the pro-apoptotic genes, that for tumor necrosis factor $\alpha$ (TNF- $\alpha$ ) exhibited the highest expression ratio (approximately six fold in the cerebellum) in the $\mathrm{Hexa}^{-/-} \mathrm{Neu}^{-/}$

mice. TNF- $\alpha$, which is involved in both pro-inflammatory and apoptotic signaling cascades, is a key mediator of inflammation as well as apoptosis. Several studies have shown that the absence of TNF- $\alpha$, leads to significantly less inflammation, apoptosis, and fibrosis (Rimkunas et al., 2009). Caspase-4 (CASP4) also exhibited a twofold increase in the cerebellum of $\mathrm{Hexa}^{-/-} \mathrm{Neu} 3^{-/-}$mice. Although CASP4 is a poorly characterized member of the caspase family, its involvement in endoplasmic reticulum stress-induced apoptosis has been suggested. The elevated levels of CASP4 suggest increased apoptosis in the cerebella and cortices of $\mathrm{Hexa}^{-/-} \mathrm{Neu}^{-/-}$mice (Sollberger et al., 2012). The early activation of astrocytes in mouse models of GM2 gangliosidoses has been reported (Kawashima et al., 2009). Of the antiapoptotic genes analyzed, the expression of Naip (neuronal apoptosis inhibitory protein-1) in $\mathrm{Hexa}^{-/-} \mathrm{Neu} 3^{-/-}$mice was dramatically decreased (approximately sevenfold in the cerebellum and three fold in the cortex) compared to Hexa $a^{-/-}$mice, indicating that NAIP1 cannot inhibit apoptosis (Lesné et al., 2005). The peroxiredoxin II (Prdx2) gene encodes a protein that reduces peroxide levels in cells. We speculate that the lower expression of this protein (approximately twofold in the cerebellum and fourfold in the cortex) in $\mathrm{Hexa}^{-/-} \mathrm{Neu} 3^{-/-}$mice might be important, because PRDX2 plays a major role in protecting red blood 
cells from oxidative stress in mice (Lee et al., 2003). X-linked inhibitor of apoptosis (Xiap) is another gene that exhibited decrease (twofold) in the cortex (Bhattacharyya and Banerjee, 1997). DNA polymerase $\beta$ (pol $\beta$ ) carries out base-excision repair (BER), which is required for DNA maintenance, replication, recombination, and drug resistance. Decreased expression of the pol $\beta$ gene (twofold in the cerebellum and 4.4 fold in the cortex) may result in mutations and, increased chromosomal damage as well as apoptosis (Sobol et al., 2000). We also observed decreased expression of genes encoding general inhibitors of apoptosis, including Bax, Bcl2, Bcl2l1, Bcl2l10, and Bcl2i12, which prevents them from inhibiting apoptosis. Glial fibrillary acidic protein (GFAP) immunohistochemistry revealed strong astrogliosis in various brain regions of $\mathrm{Hexa}^{-/-} \mathrm{Neu}^{-/-}$mice, with the most prominent GFAP staining observed in the hippocampus, cerebral cortex, and thalamus (Fig. 11). In accordance with this result, significant increases in the expression levels of the Ccl3 (MIP1 $\alpha)$ and Ccl4 (MIP1 $\beta$ ) chemokines in the cerebellum and Ccl2 as well as Ccl3 in cortex of $\mathrm{Hexa}^{-/-} \mathrm{Neu} 3^{-/-}$ mice compared to age-matched $\mathrm{Hexa}^{-/-}$mice were detected at four months of age (data not shown). Most of the progressive neuropathological changes such as the elevated astrogliosis positive cells observed in $\mathrm{Hexa}^{-/-} \mathrm{Neu}^{-/-}$mice, closely resemble those of the $\mathrm{Hexb}^{-/-}$mice model of Sandhoff disease.

\section{6. $\mathrm{Hexa}^{-/-} \mathrm{Neu} 3^{-/-}$mice exhibit gait abnormalities and motor coordination deficits}

Throughout their observed lifespans, the WT, $\mathrm{Hexa}^{-/-}$, and $\mathrm{Neu}^{-/}$ - mice were grossly indistinguishable and were grouped together as controls for all analyses. To quantify gait abnormalities in the $\mathrm{Hexa}^{-/}$ ${ }^{-} \mathrm{Neu} 3^{-/-}$mice, we analyzed their footprint patterns as they walked across a platform (Fig. 12). The Hexa ${ }^{-/-} \mathrm{Neu}^{-/-}$mice tended to stay at the start line and took longer than the WT, Hexa ${ }^{-/-}$or $\mathrm{Neu}^{-/-}$ mice to walk the length of the platform. The stride, sway, and stance lengths for the $\mathrm{Hexa}^{-/-} \mathrm{Neu}^{-/-}$mice were significantly reduced and more variable than their littermate controls. The paw prints of the mice reflect the affected neurons controlling the hind legs. Motor coordination and balance were further studied using procedures similar to our previously published methods (Seyrantepe et al., 2010). The Hexa ${ }^{-\prime}$

${ }^{-} \mathrm{Neu} 3^{-/-}$mice also exhibited progressively impaired performance on the rotarod tests that were conducted when the mice were 2.5 and 4.5 months of age. They performed poorly during the first trial of the stationary rod component compared to the control group, but then the groups performed comparably for the next three trials. The $\mathrm{Hexa}^{-\prime}$

${ }^{-} \mathrm{Neu} 3^{-/-}$mice exhibited greater performance impairments on the accelerating rotarod test (Fig. 13).

\section{Discussion}

To obtain animal models of GM2 gangliosidoses, $\mathrm{Hexa}^{-/-}, \mathrm{Hexb}^{-/}$ -, and Gm2ap ${ }^{-1-}$ knockout mice have been generated (Lawson and Martin, 2016). Naturally occurring Jacob sheep, feline, canine and flamingo models of GM2 gangliosidoses are also known to exist. Jacob sheep appear to mimic the human Tay-Sachs phenotype to a large extent, but a mouse model recapitulating the human disease could facilitate the study of disease pathogenesis. In contrast to the late-onset mild phenotype of the $\mathrm{Hexa}^{-/-}$mouse model (Miklyaeva et al., 2004), the $\mathrm{Hexa}^{-/-} \mathrm{Neu}^{-/-}$mice displayed a lethal early-onset phenotype resembling human Tay-Sachs disease. Neurological abnormalities including tremors and ataxia as well as weakened hind limbs with uncoordinated gait were observed. As in the case of patients with TaySachs disease, the $\mathrm{Hexa}^{-/-} \mathrm{Neu}^{-/-}$mice suffer from growth impairment and remain smaller than their littermates throughout their lifespan. This feature is not characteristic of the $\mathrm{Hexa}^{-/-}$mice. The $\mathrm{Hexa}^{-/-} \mathrm{Neu}^{-/-}$mice also exhibit progressive neurodegeneration and neurobehavioral abnormalities that are similar to the severe phenotype of $H e x b^{-/-}$mice (Phaneuf et al., 1996; Yamanaka et al., 1994; Sango et al., 1995). A high incidence of sudden death was also common among the Hexa ${ }^{-/-} \mathrm{Neu}^{-/-}$mice.

In this study we demonstrated that the combined disruption of the genes encoding Hexa and Neu3 blocked the degradation of gangliosides and resulted in abnormally high levels of GM2, which is consistent with the existence of a metabolic bypass pathway in mice as was predicted about 20 years ago. The minor accumulation of GA2 observed in parallel could indicate a minor contribution of NEU4 to this pathway and the subsequent trapping of GA2 in the multi-lamellar lysosomal inclusions. It is also noteworthy that lactosylceramide accumulated as much as GM3 in the brains of 4.5-month-old $\mathrm{Hexa}^{-/-} \mathrm{Neu} 3^{-/-}$mice, either by trapping in inclusions or as a result of the lack of NEU3, which would support a role of NEU3 in GM3 degradation as previously proposed (Pan et al., 2017).

Numerous efforts are being made toward the development of treatments for GM2 gangliosidoses. Like other lysosomal storage diseases, the challenge is to reach the affected cells that store accumulating macromolecules in swollen lysosomes. Approaches such as enzyme therapy (Tsuji et al., 2011), gene therapy (Bourgoin et al., 2003; Martino et al., 2005; Cachon-Gonzalez et al., 2006), substrate deprivation therapy (Platt et al., 1997; Platt and Butters, 2000; Shapiro et al., 2009; Bembi et al., 2006), and chaperone-mediated enzyme stabilization (Tropak et al., 2004) have shown various levels of success in cell cultures and some animal models, but they have yet to arrest the neurodegenerative process in human patients. Nevertheless, the recent promise of a novel self-complementary adeno-associated virus vector carrying a new variant of the human HEXA $\alpha$ subunit and its widespread distribution capacity to degrade long-standing GM2 storage in $\mathrm{Hexa}^{-1-}$ mice suggests potential for this approach in the long term (Karumuthil-Melethil et al., 2016).

Tay-Sachs is a rare childhood disease and there is limited access to brain samples for autopsy. Therefore, the onset and age-dependent morphological changes in the brain and the disease mechanisms that contribute to the neuropathology in these patients remain largely unknown. The general similarity of the $\mathrm{Hexa}^{-/-} \mathrm{Neu}^{-/-}$mouse model to human Tay-Sachs patients renders the murine model a valuable tool for studies of the pathogenesis and the cascade of events leading from lysosomal dysfunction to neurodegeneration and devastating disease in children. The feasibility of various therapeutic options including substrate deprivation and gene therapy, can be investigated with this model. Furthermore, as the rapidly progressive neurological manifestations are easily recognizable both pathologically and clinically, this mouse model is particularly useful for the evaluation of molecular therapeutic effects on the central nervous system.

Together, our findings provide compelling evidence for undertaking detailed studies to investigate the involvement of sialidase NEU3 in ganglioside degradation in the pathogenesis of Tay-Sachs disease in mice. The $\mathrm{Hexa}^{-/-} \mathrm{Neu}^{-/-}$mouse model now also provides the basis to undertake studies on human NEU3 in this mouse model in order to estimate the therapeutic potential of possible treatments. The regulation of Neu3 expression may pave the way toward novel and effective treatment options in the management of this disease.

Supplementary data to this article can be found online at https:// doi.org/10.1016/j.expneurol.2017.09.012.

\section{Acknowledgements}

The authors thank Ebru Erbay (Bilkent University, Ankara, Turkey), Barbara Triggs-Raine (University of Manitoba, Winnipeg, Canada) and Roy Gravel for helpful advice and critical reading of manuscript; Domenik Rehberger for his assistance in lipid analysis; Kyowa Hakko Kirin Co., Ltd. (Tokyo, Japan), for a generous gift of monoclonal antibodies against GM2 ganglioside. 


\section{Funding}

Major parts of this study were supported by an EMBO 2010 Installation Grant to Prof Dr. Volkan Seyrantepe. This work was also supported by grant 01DL13008 from the Bundesministerium für Bildung und Forschung to Roger Sandhoff and by allocations to Roger Sandhoff and Carsten Hopf within a joint grant ("ZAFH ABIMAS") from ZO IV by the Landesstiftung Baden-Württemberg and the Europäischer Fonds für Regionale Entwicklung (EFRE).

\section{Conflict of interests}

The authors declare no competing financial interests.

\section{References}

Albohy, A., Li, M.D., Zheng, R.B., Zou, C., Cairo, C.W., 2010. Insight into substrate recognition and catalysis by the human neuraminidase 3 (NEU3) through molecular modeling and site directed mutagenesis. Glycobiology 20 (9), 1127-1138 (Sep).

Allende, M.L., Proia, R.L., 2014. Simplifying complexity: genetically resculpting glycosphingolipid synthesis pathways in mice to reveal function. Glycoconj. J. 31, 613-622.

d'Azzo, A., Hoogeveen, A., Reuser, A.J., Robinson, D., Galjaard, H., 1982. Molecular defect in combined beta-galactosidase and neuraminidase deficiency in man. Proc. Natl. Acad. Sci. U. S. A. 79, 4535-4539.

Bembi, B., Marchetti, F., Guerci, V.I., Ciana, G., Addobbati, R., Grasso, D., Barone, R., Cariati, R., Fernandez-Guillen, L., Butters, T., Pittis, M.G., 2006. Substrate reduction therapy in the infantile form of Tay-Sachs disease. Neurology 66, 278-280.

Bhattacharyya, N., Banerjee, S., 1997. A variant of DNA polymerase acts as a dominant negative mutant (expression in tumor base excision repair DNA binding). In: Med. Sci. Commun. 94. Georg. R. Stark Cleve Clin Found, pp. 10324-10329.

Bonten, E.J., Campos, Y., Zaitsev, V., Nourse, A., Waddell, B., Lewis, W., Taylor, G., d'Azzo, A., 2009. Heterodimerization of the sialidase NEU1 with the chaperone protective protein/cathepsin A prevents its premature oligomerization. J. Biol. Chem. 284, 28430-28441.

Bourgoin, C., Emiliani, C., Kremer, E.J., Gelot, A., Tancini, B., Gravel, R.A., Drugan, C., Orlacchio, A., Poenaru, L., Caillaud, C., 2003. Widespread distribution of beta-hexosaminidase activity in the brain of a Sandhoff mouse model after coinjection of adenoviral vector and mannitol. Gene Ther. 10, 1841-1849.

Cachon-Gonzalez, M.B., Wang, S.Z., Lynch, A., Ziegler, R., Cheng, S.H., Cox, T.M., 2006. Effective gene therapy in an authentic model of Tay-Sachs-related diseases. Proc. Natl. Acad. Sci. U. S. A. 103, 10373-10378.

Fulop, A., Porada, M.B., Marsching, C., Blott, H., Meyer, B., Tambe, S., Sandhoff, R., Junker, H.D., Hopf, C., 2013. 4-Phenyl-alpha-cyanocinnamic acid amide: screening for a negative ion matrix for MALDI-MS imaging of multiple lipid classes. Anal. Chem. 85, 9156-9163.

Gravel, R.A., Kaback, M.M., Proia, R.L., Sandhoff, K., Suzuki, K., Suzuki, K., 2001. The GM2 Gangliosidosis. In: Scriver, C.R. (Ed.), The Metabolic and Molecular Bases of Inherited Disease. Scriver, C R, New York, pp. 3827-3876.

Ha, K.T., Lee, Y.C., Cho, S.H., Kim, J.K., Kim, C.H., 2004. Molecular characterization of membrane type and ganglioside-specific sialidase (Neu3) expressed in E. coli. Mol. Cell 17 (2), 267-273 (Apr 30).

Igdoura, S.A., Mertineit, C., Trasler, J.M., Gravel, R.A., 1999. Sialidase-mediated depletion of GM2 ganglioside in Tay-Sachs neuroglia cells. Hum. Mol. Genet. 6, $1111-1116$.

Karumuthil-Melethil, S., Nagabhushan Kalburgi, S., Thompson, P., Tropak, M., Kaytor, M.D., Keimel, J.G., Mark, B.L., Mahuran, D., Walia, J.S., Gray, S.J., 2016. Novel vector design and hexosaminidase variant enabling self-complementary adeno-associated virus for the treatment of Tay-Sachs disease. Hum. Gene Ther. 27 (7), 509-521 (Jul).

Kawashima, N., Tsuji, D., Okuda, T., Itoh, K., Nakayama, K., 2009. Mechanism of abnormal growth in astrocytes derived from a mouse model of GM2 gangliosidosis. J. Neurochem. 111 (4), 1031-1041 (Nov).

Kolter, T., Sandhoff, K., 1999. Sphingolipids - their metabolic pathways and the pathobiochemistry of neurodegenerative diseases. Angew. Chem. Int. Ed. 38, 1532-1568.

Lawson, C.A., Martin, D.R., 2016. Animal models of GM2 gangliosidosis: utility and limitations. Appl. Clin. Genet. 9, 111-120.

Lee, T.H., Kim, S.U., Yu, S.L., Kim, S.H., Park, D.S., Moon, H.B., Dho, S.H., Kwon, K.S., Kwon, H.J., 2003. Peroxiredoxin II is essential for sustaining life span of erythrocytes in mice. Blood 101, 5033-5038.

Lesné, S., Gabriel, C., Nelson, D.A., White, E., Mackenzie, E.T., Vivien, D., Buisson, A. 2005. Akt-dependent expression of NAIP-1 protects neurons against amyloid-\{beta $\}$ toxicity. J. Biol. Chem. 280, 24941-24947.

Marsching, C., Rabionet, M., Mathow, D., Jennemann, R., Kremser, C., Porubsky, S. Bolenz, C., Willecke, K., Grone, H.J., Hopf, C., Sandhoff, R., 2014. Renal sulfatides sphingoid base-dependent localization and region-specific compensation of CerS2Dysfunction. J. Lipid Res. 55, 2354-2369.

Martino, S., Marconi, P., Tancini, B., Dolcetta, D., De Angelis, M.G., Montanucci, P., Bregola, G., Sandhoff, K., Bordignon, C., Emiliani, C., 2005. A direct gene transfer strategy via brain internal capsule reverses the biochemical defect in Tay-Sachs disease. Hum. Mol. Genet. 14, 2113-2123.
Miklyaeva, E.I., Dong, W., Bureau, A., Fattahie, R., Xu, Y., Su, M., Fick, G.H., Huang, J.Q., Igdoura, S., Hanai, N., Gravel, R.A., 2004. Late onset Tay-Sachs disease in mice with targeted disruption of the Hexa gene: behavioral changes and pathology of the central nervous system. Brain Res. 1001, 37-50.

Miyagi, T., Yamaguchi, K., 2012. Mammalian sialidases: physiological and pathological roles in cellular functions. Glycobiology 22, 880-896.

Miyagi, T., Wada, T., Iwamatsu, A., Hata, K., Yoshikawa, Y., Tokuyama, S., Sawada, M., 1999. Molecular cloning and characterization of a plasma membrane-associated sialidase specific for gangliosides. J. Biol. Chem. 274, 5004-5011.

Monti, E., Bassi, M.T., Papini, N., Riboni, M., Manzoni, M., Venerando, B., Croci, G., Preti, A., Ballabio, A., Tettamanti, G., Borsani, G., 2000. Identification and expression of NEU3, a novel human sialidase associated to the plasma membrane. Biochem. J. 349, $343-351$.

Monti, E., Bonten, E., D'Azzo, A., Bresciani, R., Venerando, B., Borsani, G., Schauer, R., Tettamanti, G., 2010. Sialidases in vertebrates: a family of enzymes tailored for several cell functions. Adv. Carbohydr. Chem. Biochem. 64, 403-479.

Nordstrom, V., Willershauser, M., Herzer, S., Rozman, J., Bohlen Und, von, Halbach, O, Meldner, S., Rothermel, U., Kaden, S., Roth, F.C., Waldeck, C., Gretz, N., de Angelis, M.H., Draguhn, A., Klingenspor, M., Grone, H.J., Jennemann, R., 2013. Neuronal expression of glucosylceramide synthase in central nervous system regulates body weight and energy homeostasis. PLoS Biol. 11, e1001506.

Ohmi, Y., Ohkawa, Y., Yamauchi, Y., Tajima, O., Furukawa, K., Furukawa, K., 2012. Essential roles of gangliosides in the formation and maintenance of membrane microdomains in brain tissues. Neurochem. Res. 37 (6), 1185-1191 (Jun).

Pan, X., De Aragão, C.B.P., Velasco-Martin, J.P., Priestman, D.A., Wu, H.Y., Takahashi, K., Yamaguchi, K., Sturiale, L., Garozzo, D., Platt, F.M., Lamarche-Vane, N., Morales, C.R., Miyagi, T., Pshezhetsky, A.V., 2017. Neuraminidases 3 and 4 regulate neuronal function by catabolizing brain gangliosides. FASEB J. Apr 25 (pii: fj.201601299R).

Papini, N., Anastasia, L., Tringali, C., Croci, G., Bresciani, R., Yamaguchi, K., Miyagi, T., Preti, A., Prinetti, A., Prioni, S., et al., 2004. The plasma membrane-associated sialidase MmNEU3 modifies the ganglioside pattern of adjacent cells supporting its involvement in cell-to-cell interactions. J. Biol. Chem. 279, 16989-16995.

Phaneuf, D., Wakamatsu, N., Huang, J.Q., Borowski, A., Peterson, A.C., Fortunato, S.R., Ritter, G., Igdoura, S.A., Morales, C.R., Benoit, G., Akerman, B.R., Leclerc, D., Hanai, N., Marth, J.D., Trasler, J.M., Gravel, R.A., 1996. Dramatically different phenotype in mouse models of human Tay-Sachs and Sandhoff disease. Hum. Mol. Genet. 1, 1-14.

Platt, F.M., Butters, T.D., 2000. Substrate deprivation: a new therapeutic approach for the glycosphingolipid lysosomal storage diseases. Expert Rev. Mol. Med. 2, 1-17.

Platt, F.M., Neises, G.R., Reinkensmeier, G., Townsend, M.J., Perry, V.H., Proia, R.L., Winchester, B., Dwek, R.A., Butters, T.D., 1997. Prevention of lysosomal storage in Tay-Sachs mice treated with N-butyldeoxynojirimycin. Science 276, 428-431.

Pshezhetsky, A.V., Ashmarina, M., 2001. Lysosomal multienzyme complex: biochemistry, genetics, and molecular pathophysiology. Prog. Nucleic Acid Res. Mol. Biol. 69, 81-114.

Regina, T., Hakomori, S.I., 2008. Functional role of glycosphingolipids and gangliosides in control of cell adhesion, motility, and growth, through glycosynaptic microdomains. Biochim. Biophys. Acta 1780 (3), 421-433 (Mar).

Rimkunas, V.M., Graham, M.J., Crooke, R.M., Liscum, L., 2009. TNF-\{alpha\} plays a role in hepatocyte apoptosis in Niemann-Pick type C liver disease. J. Lipid Res. 2, 327-333.

Sandhoff, K., 2016. Neuronal sphingolipidoses: membrane lipids and sphingolipid activator proteins regulate lysosomal sphingolipid catabolism. Biochimie 130, 146-151 (Nov).

Sandhoff, K., Conzelmann, E., 1984. The biochemical basis of gangliosidoses. Neuropediatrics 15, 85-92 (Sep, Suppl).

Sandhoff, R., Hepbildikler, S.T., Jennemann, R., Geyer, R., Gieselmann, V., Proia, R.L. Wiegandt, H., Grone, H.J., 2002. Kidney sulfatides in mouse models of inherited glycosphingolipid disorders: determination by nano-electrospray ionization tandem mass spectrometry. J. Biol. Chem. 277, 20386-20398.

Sango, K., Yamanaka, S., Hoffmann, A., Okuda, Y., Grinberg, A., Westphal, H., McDonald, M.P., Crawley, J.N., Sandhoff, K., Suzuki, K., Proia, R.L., 1995. Mouse models of TaySachs and Sandhoff diseases differ in neurologic phenotype and ganglioside metabolism. Nat. Genet. 2, 170-176.

Schnaar, R.L., 2010. Brain gangliosides in axon-myelin stability and axon regeneration. FEBS Lett. 584 (9), 1741-1747 (May 3).

Seyrantepe, V., Canuel, M., Carpentier, S., Landry, K., Durand, S., Liang, F., Zeng, J., Caqueret, A., Gravel, R.A., Marchesini, S., Zwingmann, C., Michaud, J., Morales, C.R., Levade, T., Pshezhetsky, A.V., 2008. Mice deficient in Neu4 sialidase exhibit abnormal ganglioside catabolism and lysosomal storage. Hum. Mol. Genet. 17 (11), 1556-1568 (Jun 1).

Seyrantepe, V., Lema, P., Caqueret, A., Dridi, L., Bel Hadj, S., Carpentier, S., Boucher, F., Levade, T., Carmant, L., Gravel, R.A., Hamel, E., Vachon, P., Di Cristo, G., Michaud, J.L., Morales, C.R., Pshezhetsky, A.V., 2010. Mice doubly-deficient in lysosomal hexosaminidase A and neuraminidase 4 show epileptic crises and rapid neuronal loss. PLoS Genet. 6 (9), e1001118 (Sep 16).

Shapiro, B.E., Pastores, G.M., Gianutsos, J., Luzy, C., Kolodny, E.H., 2009. Miglustat in late-onset Tay-Sachs disease: a 12-month, randomized, controlled clinical study with 24 months of extended treatment. Genet. Med. 11, 425-433.

Sobol, R.W., Prasad, R., Evenski, A., Baker, A., Yang, X.P., Horton, J.K., Wilson, S.H., 2000. The lyase activity of the DNA repair protein beta-polymerase protects from DNA-damage-induced cytotoxicity. Nature 6788, 807-810.

Sollberger, G., Strittmatter, G.E., Kistowska, M., French, L.E., Beer, H.D., 2012. Caspase-4 is required for activation of inflammasomes. J. Immunol. 188, 1992-2000.

Tropak, M.B., Reid, S.P., Guiral, M., Withers, S.G., Mahuran, D., 2004. Pharmacological enhancement of beta-hexosaminidase activity in fibroblasts from adult Tay-Sachs and Sandhoff Patients. J. Biol. Chem. 279, 13478-13487. 
Tsuji, D., Akeboshi, H., Matsuoka, K., Yasuoka, H., Miyasaki, E., Kasahara, Y., Kawashima, I., Chiba, Y., Jigami, Y., Taki, T., et al., 2011. Highly phosphomannosylated enzyme replacement therapy for GM2 gangliosidosis. Ann. Neurol. 69, 691-701.

Wang, Y., Yamaguchi, K., Shimada, Y., Zhao, X., Miyagi, T., 2001. Site-directed mutagenesis of human membrane-associated ganglioside sialidase: identification of aminoacid residues contributing to substrate specificity. Eur. J. Biochem. 268, 2201-2208.

Yamaguchi, K., Hata, K., Koseki, K., Shiozaki, K., Akita, H., Wada, T., Moriya, S., Miyagi, T., 2005. Evidence for mitochondrial localization of a novel human sialidase (NEU4). Biochem. J. 390, 85-93.

Yamaguchi, K., Shiozaki, K., Moriya, S., Koseki, K., Wada, T., Tateno, H., Sato, I., Asano, M., Iwakura, Y., Miyagi, T., 2012. Reduced susceptibility to colitis-associated colon carcinogenesis in mice lacking plasma membrane-associated sialidase. PLoS One 7
(7), e41132.

Yamanaka, S., Johnson, M.D., Grinberg, A., Westphal, H., Crawley, J.N., Taniike, M., Suzuki, K., Proia, R.L., 1994. Targeted disruption of the Hexa gene results in mice with biochemical and pathologic features of Tay-Sachs disease. Proc. Natl. Acad. Sci. U. S. A. 91, 9975-9979.

Yuziuk, J.A., Bertoni, C., Beccari, T., Orlacchio, A., Wu, Y.Y., Li, S.C., Li, Y.T., 1998. Specificity of mouse GM2 activator protein and $\beta$-N-acetylhexosaminidases A and B. Similarities and differences with their human counterparts in the catabolism of GM2. J. Biol. Chem. 273 (1), 66-72 (Jan 2).

Zanchetti, G., Colombi, P., Manzoni, M., Anastasia, L., Caimi, L., Borsani, G., Venerando, B., Tettamanti, G., Preti, A., Monti, E., Bresciani, R., 2007. Sialidase NEU3 is a peripheral membrane protein localized on the cell surface and in endosomal structures. Biochem. J. 408, 211-219. 